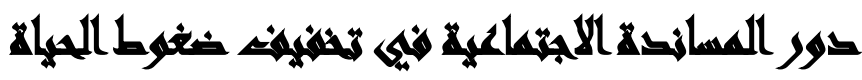

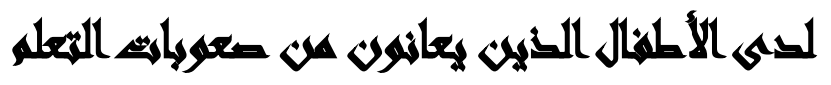

[०]

\author{
ليلي كرم الدين(')- أحمد عبد المنعم (Y) - سامية موسى مدني

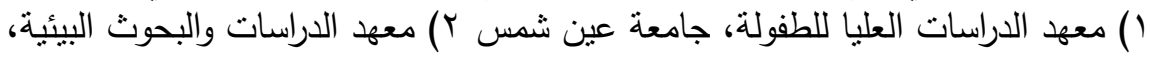 \\ جامعة عين شمس معس
}

\begin{abstract}
المسترفن

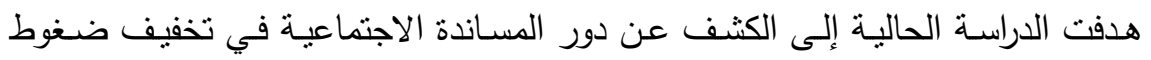

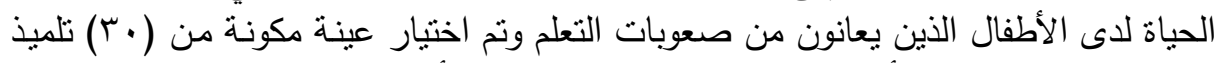

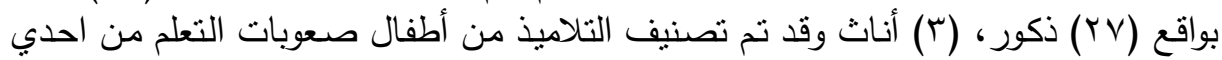

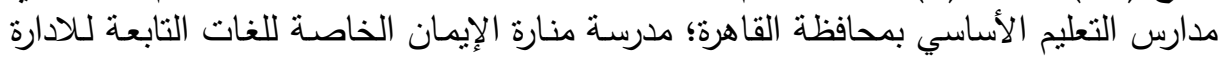

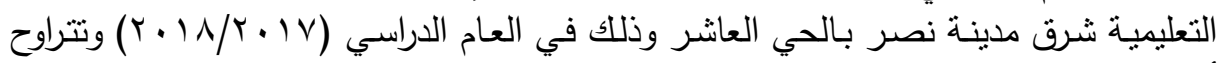

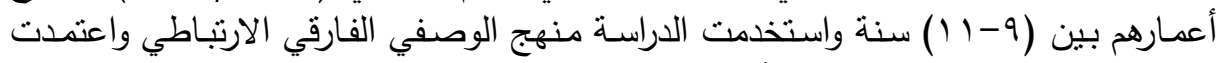

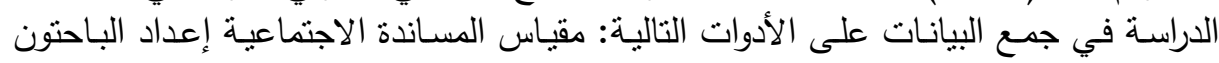

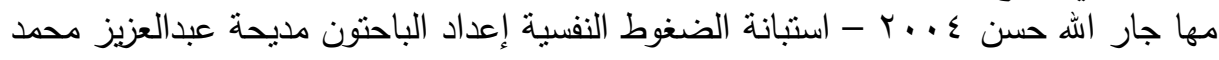

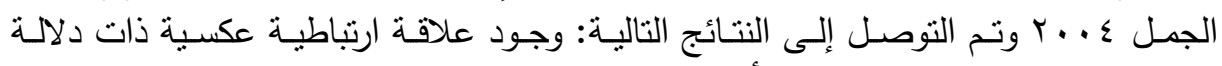

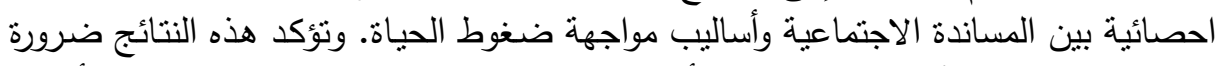

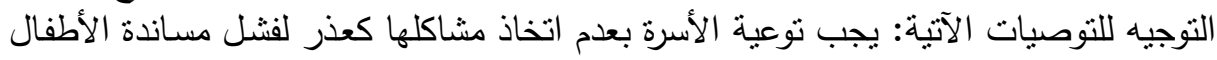

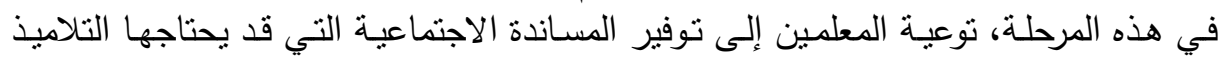

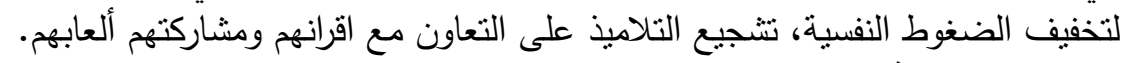

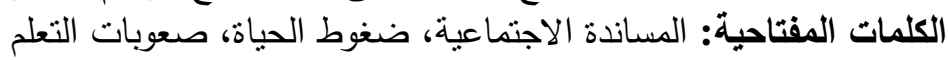

\section{$M$}

إن ما يتلقاه الفرد من دعم ومساعدة من قبل الأفراد المحيطين، أو من قبل أي فرد في

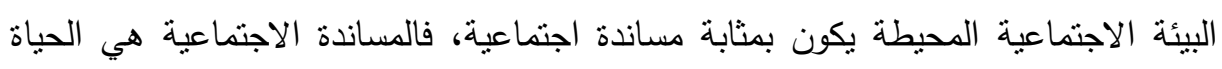
والأمن التي يحصل عليها الأفراد من خلال شبكة العلاقات الاجتماعية بينهم. 
وتتسع دائرة المساندة الاجتماعية لتشمل الأسرة والأقارب، الأصدقاء وشبكة العلاقات الاجتماعية للفرد، هذا بالإضافة للمؤسسات الاجتماعية ذات العلاقة وسائل الإعلام والمساجد الإداء

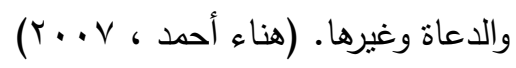

أصبحت الضغوط التي تحيط بالفرد من كل جانب كثثرة ومتعددة وذات درجات متفاوتة،

وقد يرجع ذلك إلى التغيرات التي طرأت على حياة الإنسان الأسرية والمهنية والاجنماعية.

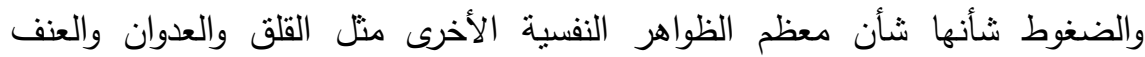

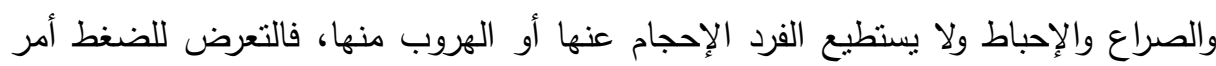
حتمي لا مفر منه لدرجة أن كلمة ضغوط الحياة تستخدم على نطاق واسع، وصارت تتردد على ألسنة الكثير من الناس وتستخدم في لغة الحياة اليومية وفي العديد من السياقات المختلفة وإن كان هنالك غموض يحيط بتعريفها، فكل شخص صار يتحدث عن ضغوط الحياة، فرجال

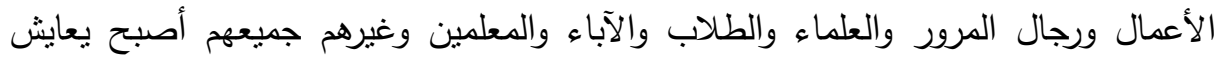

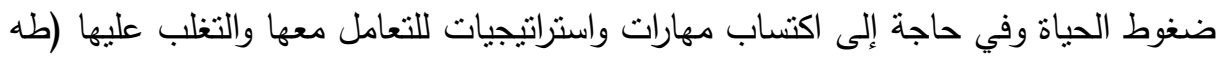

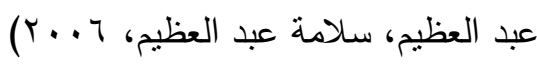
تصف أدبيات التربية الخاصة صعوبات التعلم بأنها إعاقة خفية محيرة، فالأطفال الذين يعانون من هذه الصعوبات يمتلكون قدرات تخفي جوانب الضعف في أدائهم، فهم قد يسردون

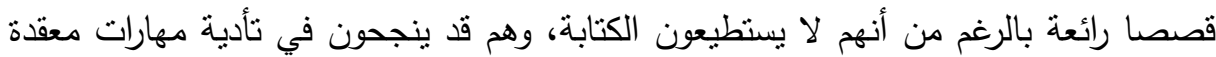

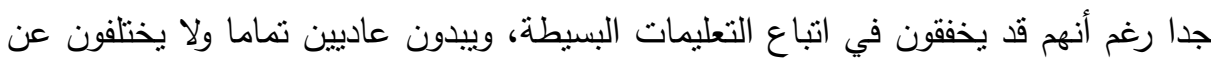

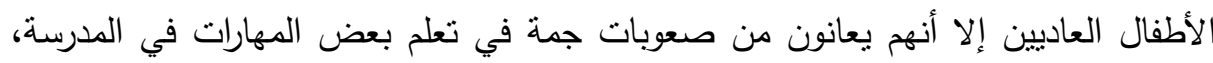

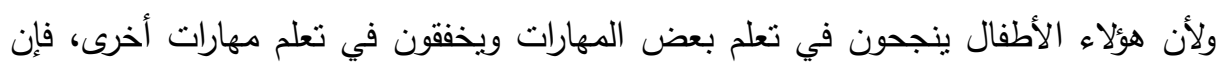

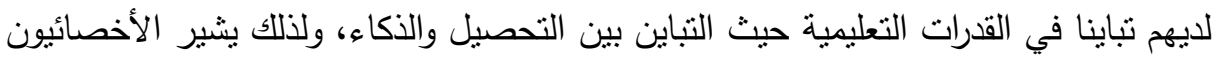
إلى أن المشكلة الرئيسية المميزة لصعوبات التعلم هو التفاوت بين الأداء والقابلية. (سليمان 


\section{مفحلة التراسمة}

تلعب المساندة الاجتماعية دورا أساسيا في تخفيف ضغوط الحياة لدى أطفال صعوبات

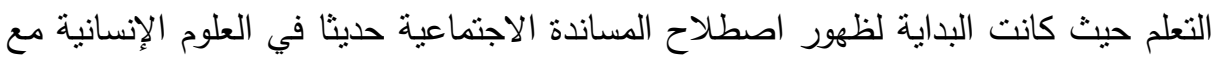
تتاول علماء الاجتماع لهذا المفهوم في إطار تتاولهم للعلاقات الاجتماعية والذي بطلق عليه

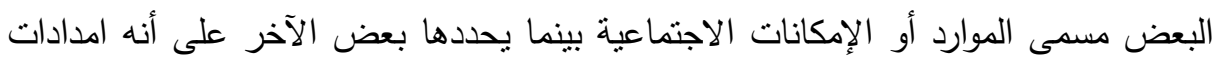

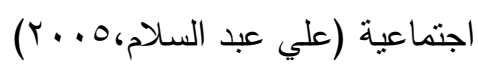

وبذلك فإن مساندة الأهل الاجتماعية أو المجتمع في تخفيف ضغوط الحياة النفسية لاى الأطفال الذين يعانون من صعوبات التعلم أساسية حيث أنها تساندهم وتضع الثقة فيهم وتكون عونا لهم في تخطي ضغوط الحياة التي لا حصر لها. (نادية محمود، ساهر زهران، 1 ( • ب) ومن هنا يظهر دور المساندة الاجتماعية في التخفيف من وقع ضغوط الحئ الحياة التي تجعل الفرد يواجه هذه الضغوط ليكون أكثر ثقة بالنفس وأكثر قوة. ومما لا شك فيه أن الأطفال

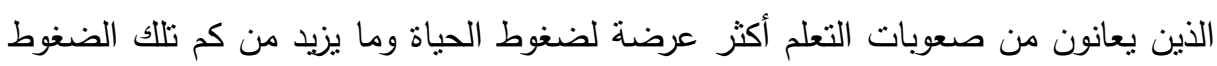
قلة دور المساندة الاجتماعية أو عدم إدراك الأهالي للمشكلة التي يعاني منها طفالهم وشعورهم

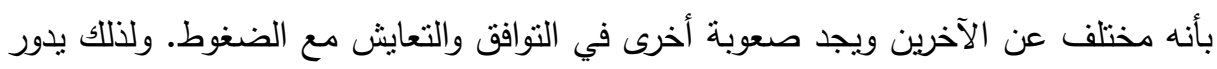

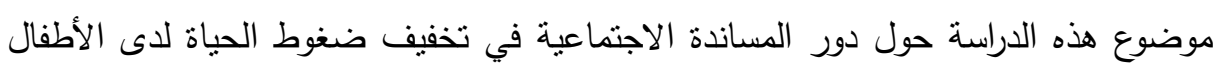

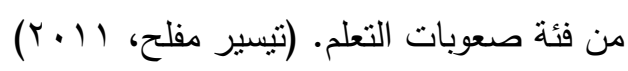

مما تقدم وتبين لنا مشكلة الدراسة وهي دور المساندة الاجتماعية في التخفيف من حدة،

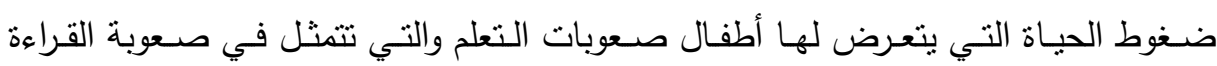

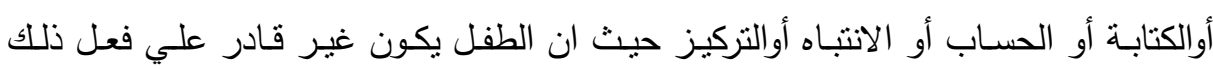

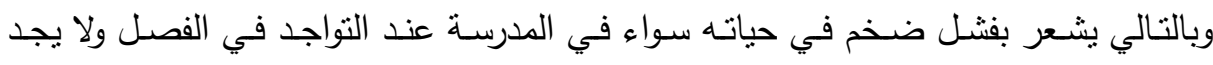
مساندة من المعلم أو الاقران وعدم مشاركتهم اللعب معه مما يؤدي الي انطواء الطفل أو عند فئد

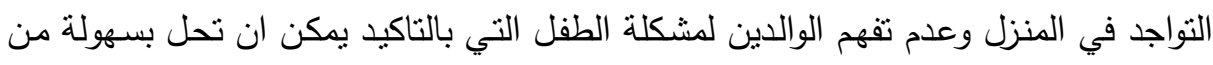

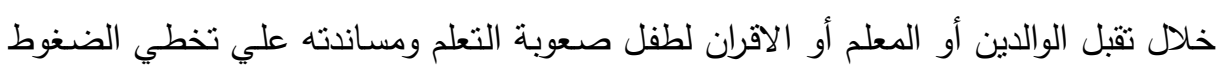

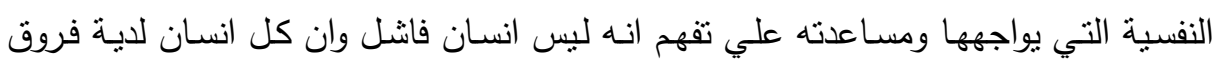

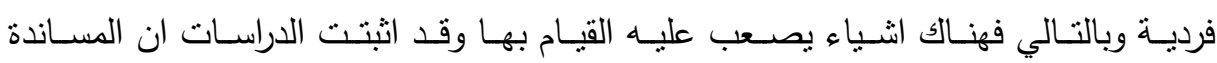

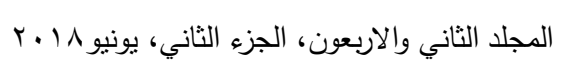


الاجتماعيـة تساعد طفل صسوبات التعلم علي تخطي مشكلاته ومنحسه الامـان والثقة وذللك

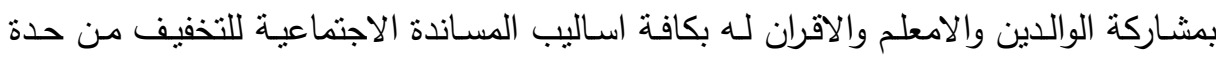

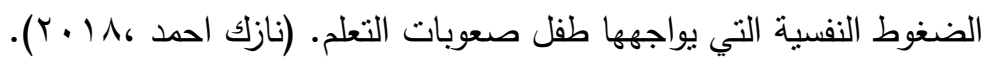

\section{توساولالاهث التصواسمة}

ا ـ مـا مدى وجود علاقة المساندة الاجتماعية وأساليب مواجهة ضغوط الحياة لدى الأطفال

$$
\text { الذين يعانون من صعوبات التعلم؟ مأ }
$$

r. ما مدى وجود فروق بين الأطفال ذوي صعوبات التعلم الذين يتلقون مسـاندة اجتماعية والذين لا يتلقون مساندة اجنماعية ويتعرضون لضغوط حياتية؟ r. مـا مدى تأثثير نوع الطفل صـوبات التعلم علي مسنتوي المسـاندة الاجتماعيـة المطلوبـة للتغلب علي الضغوط الحياتية؟

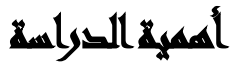

تسنمد هذه الدراسة أهميتها من العينة التي تجري عليها الدراسة وهي فئة صعوبات

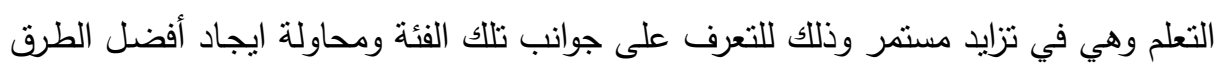
للتعامل معها حتى يستطيعوا الحصول على الثقة بالنفس والعون الحقيقي في الحياة، مما يعود بالفائدة على كل من أطفال صعوبات التعلم، وعلى أسرهم، والمعلم بالمدرسة.

\section{أهسانهم التوراسة}

الهُف الرئيسي: التعرف على نوع العلاقة بين المساندة الاجتماعية وأطفال ذوي صعويات التعلم الذين يتعرضون لضغوط حياتية

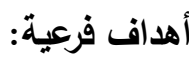

التعرف على فروق بين الأطفال ذوي صعوبات التعلم الذين يتلقون مساندة اجتماعيـة

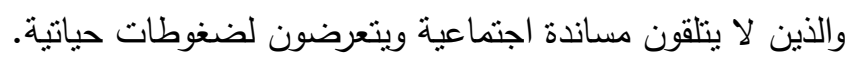


• التعرف على دور أنظمة المساندة الاجتماعية في مواجهة ضغوط أحداث الحياة يفيد ذلك

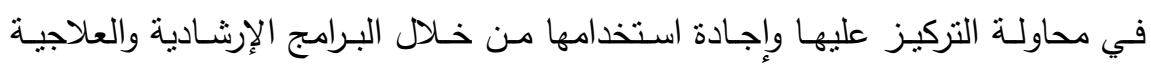
لأطفال ذوي صعوبات التعلم من فئة ذكور أو إناث.

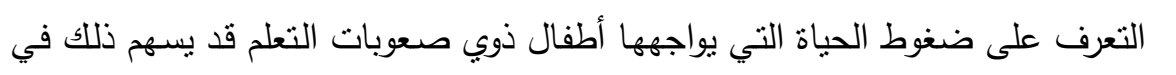
مساعدة الباحثين على تصميم برامج إرشادية في مساعدة أطفال ذوبي صعوبات التعلم على مواجهة هذه الضغوط بشكل ايجابي وفعال.

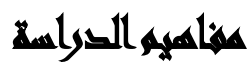

ا - مفهوم المساندة الاجتماعية: (social support): تلك العلاقات المساندة للفرد،

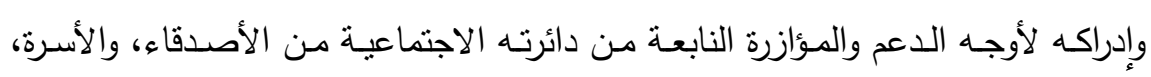

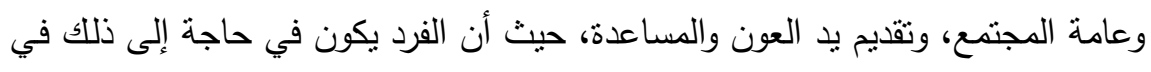

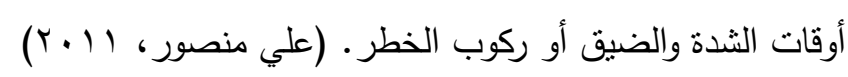
ץ- مفهـوم ضـغوط الحيـاة: ( pressures of life): تعتبر الضـغوط مـن أهم الموضوعات التي تطورت في مجتمعنا الحالي ويتفق غالبية الباحثين على أن(سيلي)هو الرائد الأول الذي قدم مفهوم ضغوط الحياة إلى الحياة العلمية ،

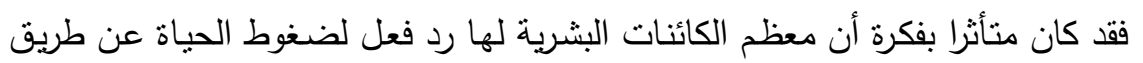

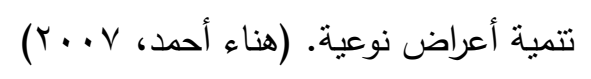
r- مفهوم صعويات التعلم: (learning difficulties): تصف أدبيات التربية الخاصة

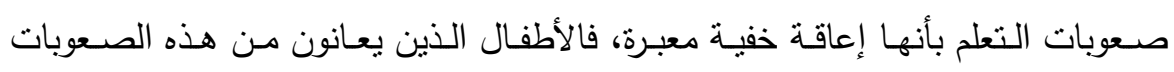

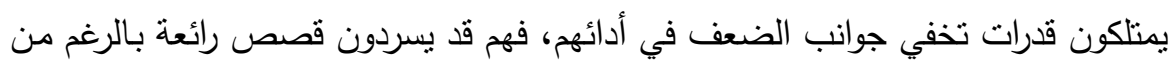

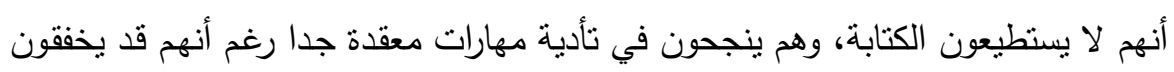

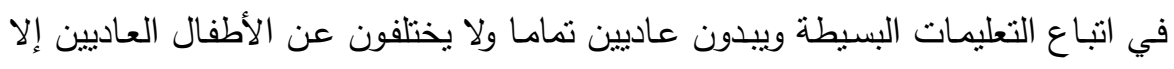

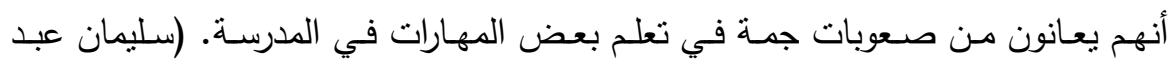

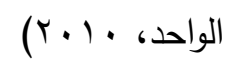




\section{الترواسايت الماريه}

( ) دراسـة محمد عودة ( • Y): هدفت الدراسة إلى التعرف على العلاقة بين درجة

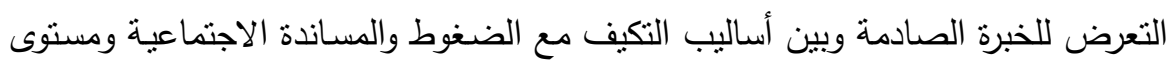
الصلابة النفسية لدى الأطفال في المناطق الحدودية بقطاع غزة، وبتحقيق غايات الدراسة

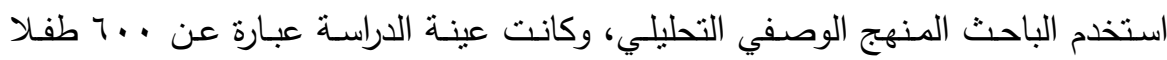

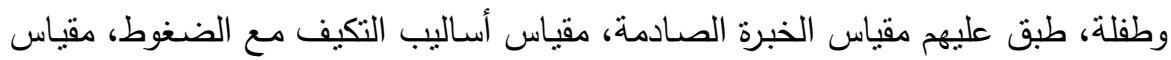
المساندة الاجتماعية، مقياس الصلابة النفسية، وأظهرت النتائج أن الأوزان النسبية لتقديرات

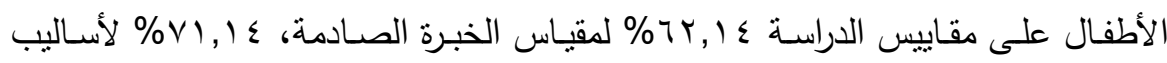

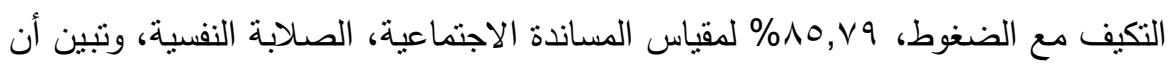
هنالك علاقة طردية بين درجة التعرض لخبرة صادمة أساليب التكيف مع الضغوط المساندة الاجتماعية، الصلابة النفسية.

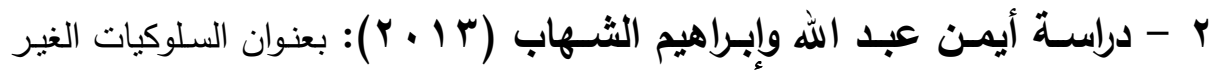

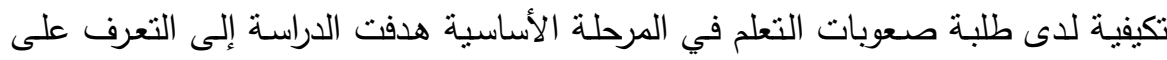
السلوكيات غير التكيفية لدى طلبة صعوبات التعلم في المرحلة الأساسية ومقارنتها بالطلبة

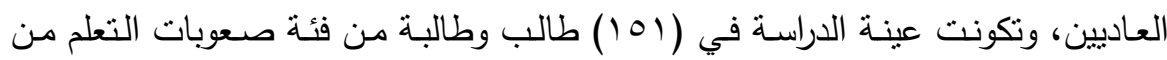

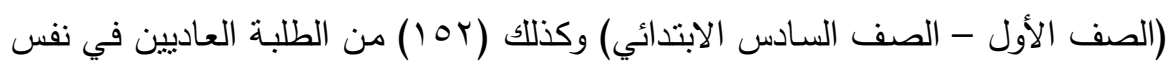
هذه المدارس ونفس المرحلة العمرية، ولقد استخدم الباحثات مقياس (وولكي) للسلوكيات

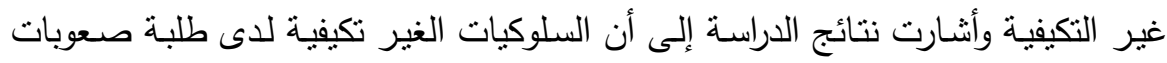
التعلم هي : السلوك الموجـه نحو الخارج، ثم تشتت الانتباه ثم العلاقات المضطربة مـع إنه

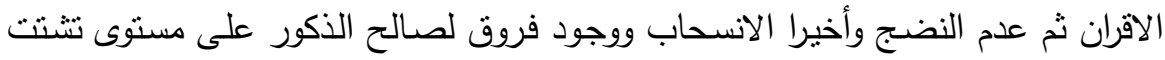
الانتباه، ولصالح الإناث على مستوى النضج. 


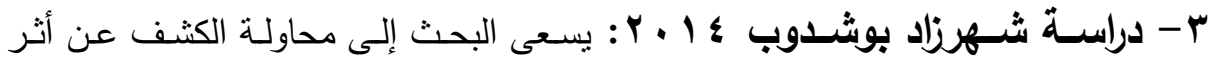

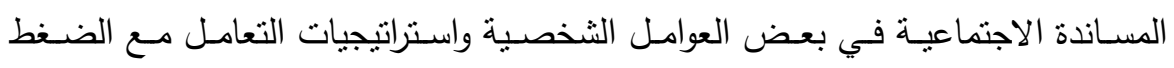

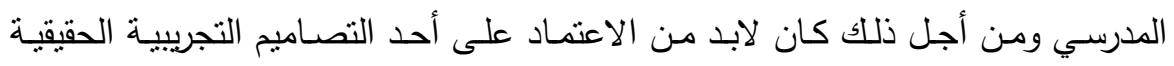

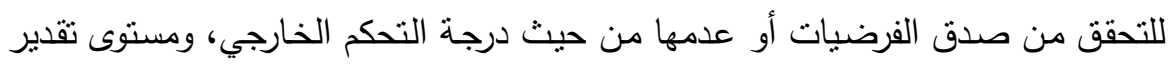

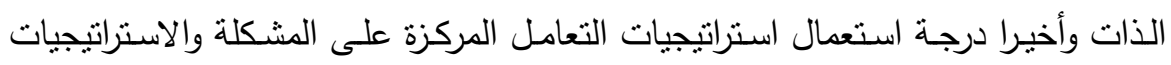

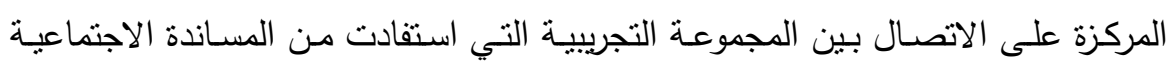

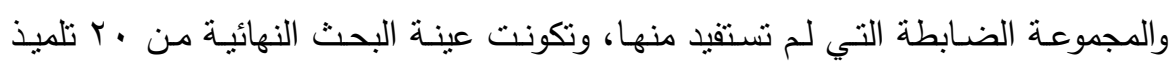

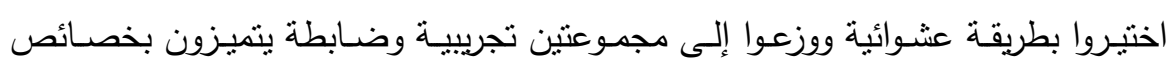

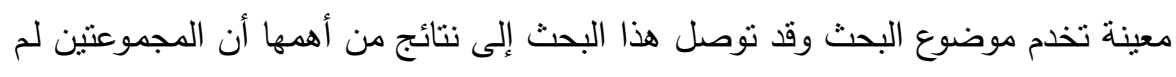

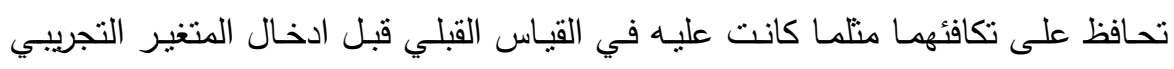

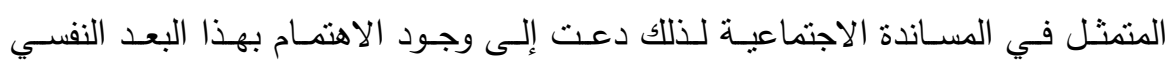
الاجتماعي نظرا لدوره الحيوي الذي يلعبه في الحياة.

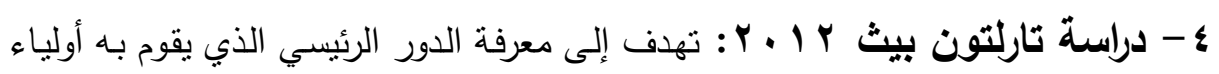

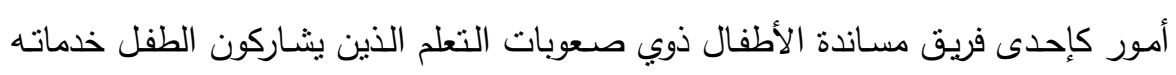
وأوضحت الدراسة أن الفريق يعمل من خلال مسنويات هي تمكين أولياء الأمور من تقديم

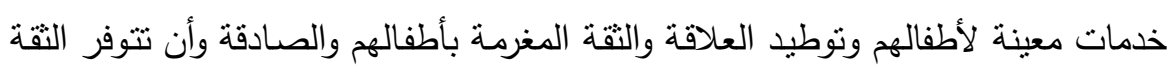
لدى فريق العمل من تجاه الوالدين والترام فريق العمل بتحقيق ماهية للأطفال وتقديم الدعم

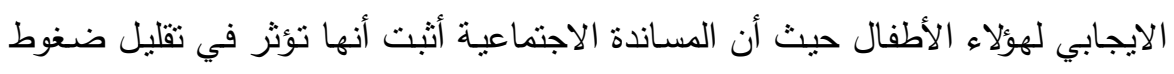

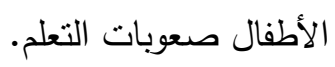

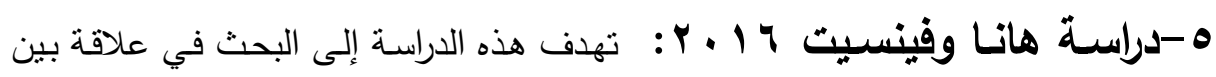

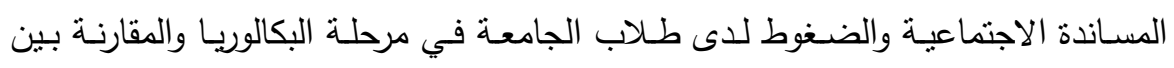

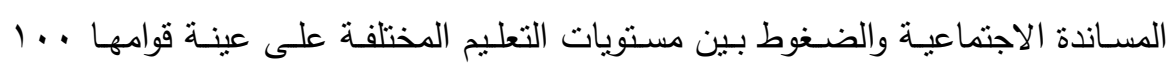

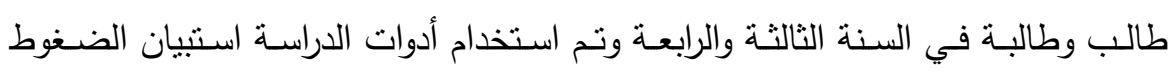

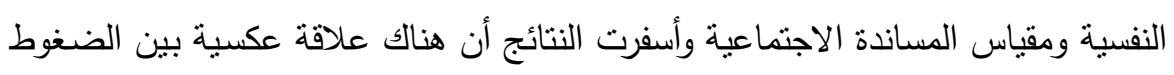


والمساندة الاجتماعية حيث أن الطلاب الذين يحصلون على مساندة اجتماعية يعانون من ضغوط نفسية قليلة.

التعقيب علي الدراسات السابقة: بعض دراسات اتفقت مع دراسة الباحنون في وجود علاقة بين المساندة الاجتماعية وأساليب مواجهة ضغوط الحياة، وتأثير جنس الطفل ذوي درابه

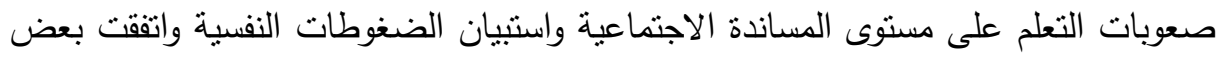
الدراسات مع أهداف دراسة الباحتون في ضرورة وجود دور لأنظمة المساندة الاجنماعية

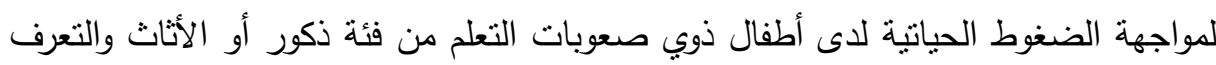

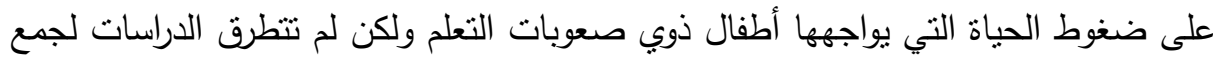

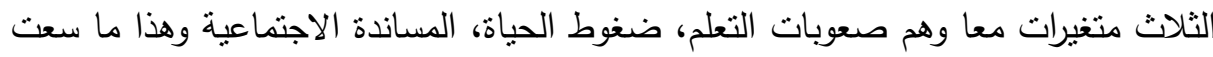
الباحتون إلى دراسته ومناقتته في الدراسة حتى يتلقى أطفال ذوبي صعوبات التعلم المساندة

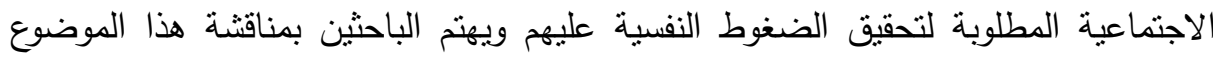

\section{الإطالر اللهظلويه}

النظريات المفسرة لضغوط الحياة: أولاً: النظريـة البيئية: الضغوط باعتبارها عامل مستقل، ينشأ عندما تتضمن البيئة ما يسبب الانزعاج للفرد وإيقاع الأذى به، الأمر الذي يمثل حمل ثقيل على كاهله وعندئد يشعر بالمشقة

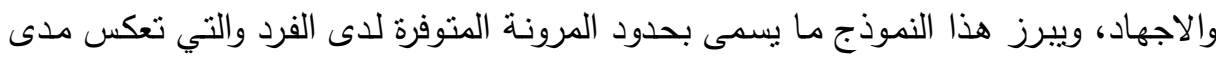
تحمله لارجة المشقة حتى يستعيد توازنه البدني له، وقد يؤدي هذا الموقف إلى حدوث أضردار

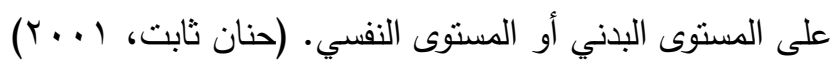

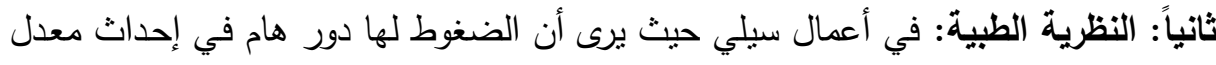
عال من الإنهاك الذي يصيب الجسم فأي إصابة جسمية أو حالة إنفعالية غير سارة كالقلق

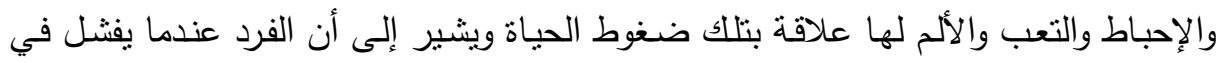


مقاومـة المصـدر المثير للضـغط فإنـهـ يكون معرض للإصـابة بـأمراض التكيف. (عطـاف

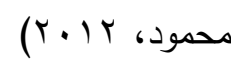
ويتتاول سيلي ضغوط الحياة في ثلاثة مراحل: أ- مرحلة التتبيه: فيها يحدث استثارة الفرد من خلال المنبه أو المثير ويستجيب الجسم بإفراز الهرمونات بهدف توفير الطاقة اللازمة لمواجهة الهدف المهدد.

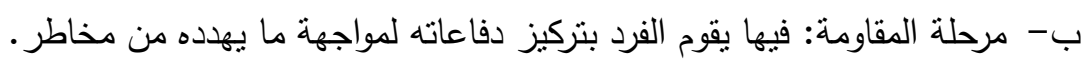

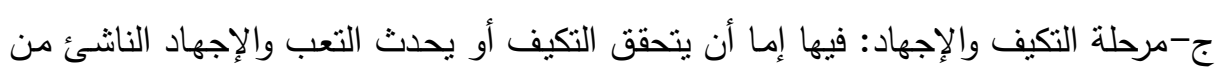
الإحساس بالخوف والتهديد الأمر الذي يؤثز بطبيعة الحال على كافة أجزاء الجسم فتظهر

أعراض منها: انخفاض مقاومة الفرد للالتهابات، تأخر النمو في الأنسجة الجديدة.

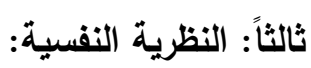
نظريـة لازاروس Lazarus : يبين أن الفرد يقوم في مواجهة الضغوط بتقيبم المواقف التي ئي

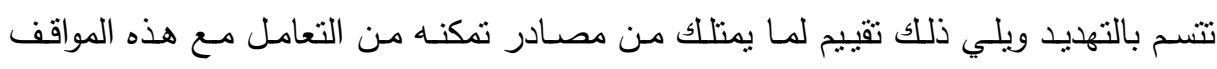

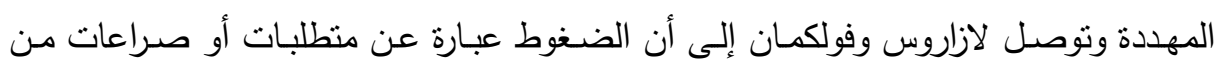
شأنها تلقي على الفرد أو على من يتوفر لديه من مصادر سواء داخليا أو خارجيا عبئا نقيلا

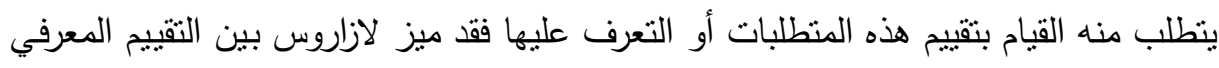

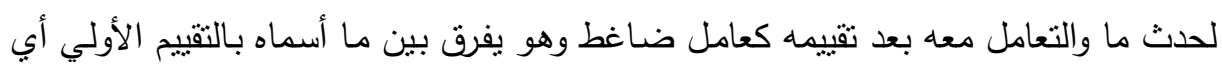

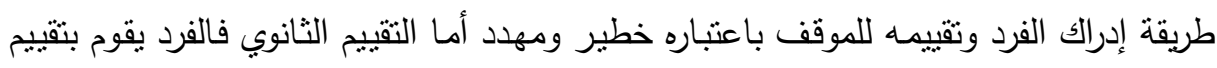
ما يمتلكه من مصادر اجتماعية وشخصية يمكن أن تعينه على التأقلم مع ما يدركه من تهديد،

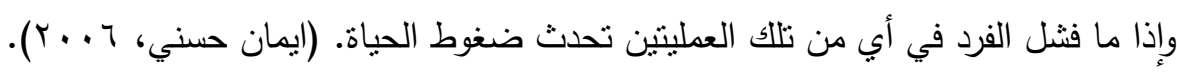

\section{إجهاعاهي الصواسة}

منهج الدراسة: من أجل تحقيق أهداف البحث سنقوم الباحتون باستخدام المنهج الوصفي الفارقي الارتباطي حدود الاراسة: تتمثل حدود البحث في الآتي:

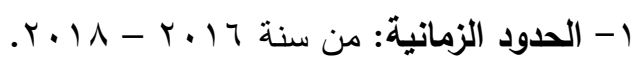

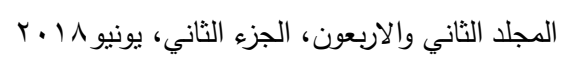


r-عينة البحث: اقتصرت عينة البحث على • ب تلميذ بواقع (YV) ذكور، (r) إناث وقد تم

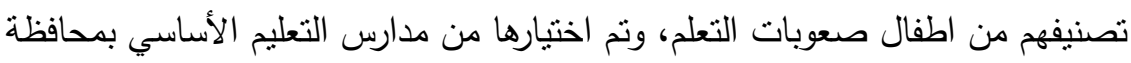

$$
\text { القاهرة (مدرسة منارة الإيمان الخاصة للغات). }
$$

خصائص عينة الاراسـة: سوف نستخدم الدراسة على نوع من العينات المطلق عليها العينة

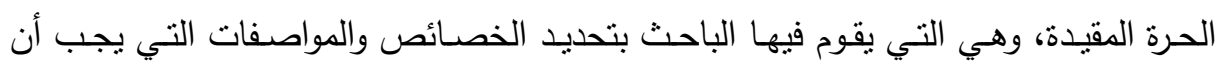
تتوافر في العينة من مدى عمري ومسنوى تعليمي ثم يترك حدا في اختيار من بين عدد من

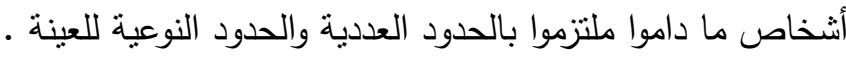

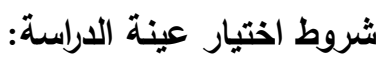

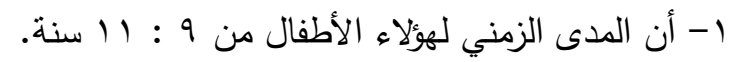
r-أن تكون من تلاميذ الصفين الثالث والرابع الابتدائي.

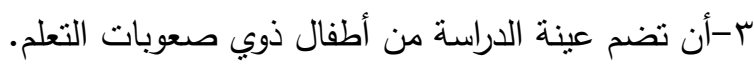
ع -أن تكون من الذكور والإناث.

\section{أسوامث السواسمة}

1-مقياس المساندة الاجتماعية أعداد الباحثة مها جار الله حسن ؟ . . ب، يتكون من ثلاثة

$$
\text { أبعاد وكل بعد يحتوي على عشر أسئلة. }
$$

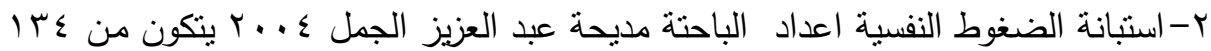
سؤال.

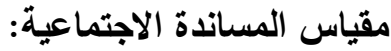

ثبات المقباس:

1-تم حساب ثبات المقياس بطريقة إعادة النطبيق، وقد روعي في إعادة نطبيقه أن تكون بعد

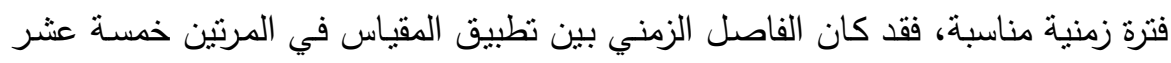
يوما، واستخدم الباحتون معادلة بيرسون لحساب معامل الارتباط بين نتائج التطبيق الأول 
والتطبيق الثاني، وكان معامل الارتباط الناتج هو 101, • بالنسبة للأسرة، . ^, • بالنسبة

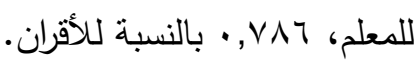
جدول رقم (1): معاملات ثبات وصدق مفردات مقياس المساندة الاجتماعية

\begin{tabular}{|c|c|c|c|c|}
\hline معامل ثبات & المفردة منف المحلف درجة & معامل الارتباط & المفردة & المحور \\
\hline \multirow{10}{*}{$\cdot, \vee \cdot$} &., 79 & $\cdot, \Gamma \wedge$ & 1 & \multirow{10}{*}{ الأول : الأسرة } \\
\hline & $\cdot, 7 \wedge$ & $\cdot, 0$. & T & \\
\hline & $\cdot, 79$ & $\cdot, \leqslant 1$ & $r$ & \\
\hline & $\cdot, 7 \wedge$ & $\cdot, 01$ & $\varepsilon$ & \\
\hline & $\cdot, 79$ & $\cdot, \leqslant 1$ & 0 & \\
\hline & $\cdot, 7 V$ & $\cdot, 0 \leqslant$ & 7 & \\
\hline & $\cdot, 7 V$ & $\cdot, 0 T$ & $\mathrm{~V}$ & \\
\hline & $\cdot, 7 \wedge$ &., 01 & $\Lambda$ & \\
\hline & $\cdot, 7 \wedge$ & $\cdot, \leqslant 7$ & 9 & \\
\hline & $\cdot, 7 \wedge$ & $\cdot, 0 Y$ & 1. & \\
\hline \multirow{10}{*}{$\cdot, V Y$} & $\cdot, \mathrm{VI}$ & $\cdot, \varepsilon$. & 1 & \multirow{10}{*}{ الثاني : المعلم } \\
\hline & $\cdot, 79$ & $\cdot, 01$ & $r$ & \\
\hline & $\cdot, 7 \wedge$ & $\cdot, 77$ & $r$ & \\
\hline & $\cdot, 79$ & $\cdot, 01$ & $\varepsilon$ & \\
\hline & $\cdot, 71$ & $\cdot, V_{1}$ & 0 & \\
\hline & $\cdot, 79$ & $\cdot, 0$ & 7 & \\
\hline &., 79 & $\cdot, O Y$ & $\mathrm{~V}$ & \\
\hline & $\cdot, \vee \cdot$ & $\cdot, 01$ & $\Lambda$ & \\
\hline & $\cdot, V_{1}$ & $\cdot, \varepsilon \Gamma$ & 9 & \\
\hline & $\cdot, \mathrm{VI}$ & $\cdot, \mu V$ & 1 . & \\
\hline \multirow{10}{*}{$\cdot, T V$} & $\cdot, 7 \varepsilon$ & $\cdot, \leqslant 0$ & 1 & \multirow{10}{*}{ الثالث: الأقران } \\
\hline & $\cdot, 70$ & $\cdot, r q$ & $r$ & \\
\hline & $\cdot, 70$ & $\cdot, \Sigma Y$ & $\mu$ & \\
\hline & $\cdot, 7 \varepsilon$ & $\cdot, \leqslant 9$ & $\varepsilon$ & \\
\hline & $\cdot, 7 \pi$ & $\cdot, 0 Y$ & 0 & \\
\hline & $\cdot, 70$ & $\cdot, \varepsilon \cdot$ & 7 & \\
\hline & $\cdot, 77$ & $\cdot, Y V$ & $\mathrm{~V}$ & \\
\hline &., 70 &.,$\mu_{0}$ & $\Lambda$ & \\
\hline & $\cdot, 7 \varepsilon$ & $\cdot, \leqslant 9$ & 9 & \\
\hline & $\cdot, 70$ & $\cdot, r_{0}$ & 1. & \\
\hline
\end{tabular}


مجلة العلوم البيئية

معهد الدراسات والبحوث البيئية - جامعة عين شمس لهن 


\section{صدق المقياس:}

1-اعتمد على صدق المحكمين في إعداد المقياس، فقد تم عرض المقياس على مجموعة من المحكمين مكونة من (9) محكمين من المتخصصين في مجال علم النفس، وأجمعت لجنة

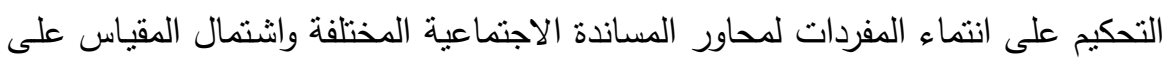

$$
\text { الأهداف المراد قياسها. }
$$

r-سيتم حساب معامل الإرتباط بين الدرجة الكلية لكل محور من محاور المقياس والدرجة

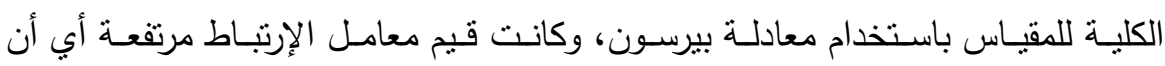

$$
\text { المقياس يتمتع بدرجة مقبولة من صدق المفردات. }
$$

جدول رقم (ץ): نتائج معاملات الإرتباط بين الدرجة الكلية لكل محور والدرجة الكلية لمقياس

\begin{tabular}{|c|c|}
\hline معامل الارتباط & المحاور \\
\hline${ }^{* * *,} \cdot T \leq Y$ & الأسرة \\
\hline$* *, 0.0$ & المعلم \\
\hline$* *, V \cdot V$ & الأقران \\
\hline
\end{tabular}
المساندة الاجتماعية

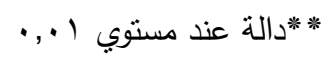

ب-تم حساب صدق المفردات من خـلال حساب معاملات الارتباط بين درجات كل مفردة

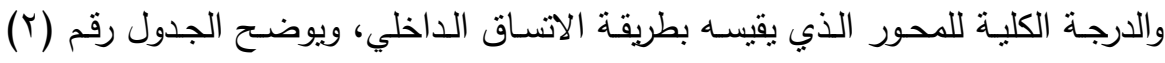

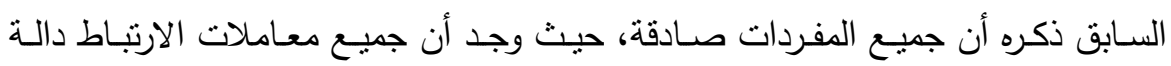

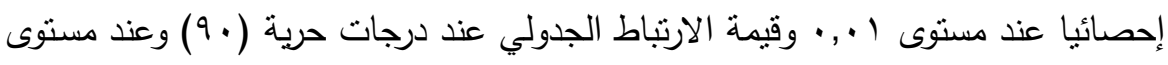

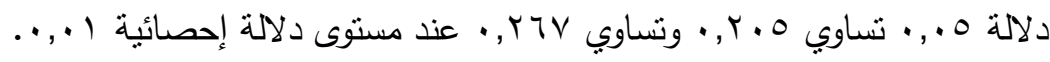




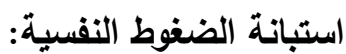

صدق الاستبانة: تم حساب الصدق بالطرق الآتية:

(أ) الصدق الظطاهي: وأهم أركانه:

1- الاطـلاع على الدراســات والمقـاييس السـيكولوجية فـي مجـال الضــوط النفسـية

$$
\text { وصعوبات التعلم. }
$$

r- إجراء مقياس في صورته الأولية.

r- تحديد الهدف من المقياس.

ع - صياغة تعليمات المقياس على نحو ينسم بالبساطة.

0- التأكد من صحة ووضوح العبارات.

(ب) صدق المحكمين: بهدف هذا النوع من الصدق إلى الحكم على تمثيل المقياس للموضوع

الذي يقيسه على نحو يتسم بالوضوح.

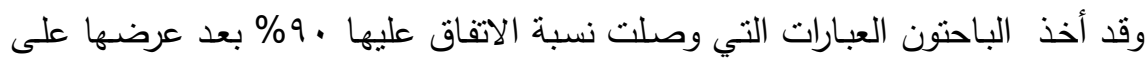

(9) محكما من الأساتذة في تخصص علم النفس والصحة النفسية والطفولة.

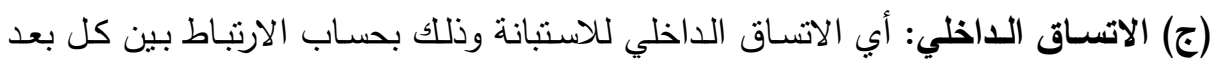

والدرجة الكلية للاستبانة وهو يعبر عن الصدق الداخلي. 
جدول رقم (ץ): القيم التقديرية لمعاملات الصدق لبنود مقياس الضغوط النفسية المرتبطة بصعوبات التعلم بطريقة تحليل البنود

\begin{tabular}{|c|c|c|c|c|c|}
\hline ارتباط البند بالمقياس الفرعي & رقم & ارتباط البند بالمقياس & رقم & ارتباط البند بالمقياس & رقم \\
\hline$* *, 7 \neg \leq 1$ & $\varepsilon V$ & $* *, 9 \leqslant Y \wedge$ & $r \leq$ & $* *, \vee \vee \neg 9 r$ & 1 \\
\hline$* *,, 7 \leqslant \Lambda$. & $\varepsilon \wedge$ & $* *,, \vee q \varepsilon 1$ & ro & $*$, * $\{\wedge \circ \Gamma$ & r \\
\hline$* *,, T \vee \neg Y$ & $\leqslant 9$ & $* *, 71 \Gamma q$ & rq & $* ., 001 \mu$ & r \\
\hline$* *, \vee \vee \neg \leq 0$ & 0 . & $* ., \Sigma q \vee r$ & $r v$ & 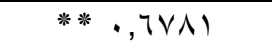 & $\varepsilon$ \\
\hline$* *, 7,00$ & 01 & $* *,, \vee \vee Y Y$ & $r_{\Lambda}$ & $* *,, 0 \wedge \vee \wedge$ & 0 \\
\hline$* *,, \wedge 90 \leqslant$ & or & $* * \cdot, V \cdot r q$ & rq & $* *, \wedge I Y$ & 7 \\
\hline$* *,, \wedge \leqslant \wedge \neg$ & or & $*, 0 \leqslant V T$ & r. & $* *, \vee \vee \neg \wedge$. & V \\
\hline$* *,, \vee 0 \leqslant \Lambda$ & $0 \leqslant$ & $* ., 0 \leqslant 7 V$ & r & $* * \cdot, O \wedge \mu V$ & $\wedge$ \\
\hline$* *, 7707$ & 00 & $* *,, v 01 r$ & rt & $* \cdot, \leqslant \leqslant \vee \leqslant$ & 9 \\
\hline$* *, \vee \vee \wedge \circ \wedge$ & 07 & $* *,, T \vee \vee$. & س & $*, 0,70$ & 1. \\
\hline$* *,, \vee 7,9$ & or & $* *, \vee, q r$ & r & 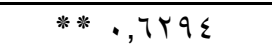 & 11 \\
\hline$* *, \vee \vee \neg 4 I$ & $\Delta \wedge$ & $* ., 10.1$ & ro & $* *,, \vee \wedge \wedge 0$ & Ir \\
\hline$* *,, V \Gamma, T$ & 09 & $* *,, \vee \backslash 0 \wedge$ & דיץ & $* ., 0 \leqslant \cdot 9$ & M \\
\hline$* *$, , ^YO. & 7. & $* *,, 91 \leq V$ & rV & $* *,, 7947$ & $1 \leqslant$ \\
\hline$* *, \wedge T \vee 0$ & 71 & $* *, 0 \wedge, 0$ & $r \wedge$ & $* *, 907 r$ & 10 \\
\hline ** , TVVr & $7 r$ & $* ., \Sigma q \vee r$ & $r q$ & $* * \cdot, \wedge \backslash 9 Y$ & 17 \\
\hline$* *,, O Y \backslash \leq$ & 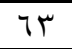 & $* *,, O \vee Y$. & $\varepsilon$. & $* ., 0 \leqslant \cdot 1$ & iv \\
\hline$* *,, \vee 701$ & $7 \varepsilon$ & $* * ., 790 \leqslant$ & \& & $* *,, 7 \backslash<q$ & 11 \\
\hline$* *, 90 \leqslant r$ & 70 & **, & $\varepsilon r$ & $* *,, 7 \vee 97$ & 19 \\
\hline$* * \cdot, q r T V$ & 77 & $* * \cdot, \wedge \neg \wedge \vee$ & $\varepsilon r$ & $* ., 01 Y 7$ & $r$. \\
\hline$* *,, \vee 99 r$ & $7 V$ & $* *,, 7 \leq \Gamma \leq$ & $\varepsilon \varepsilon$ & $* *, 70 \mathrm{Vr}$ & YI \\
\hline$* *, 7971$ & 71 & $* *,, T 1 \leqslant r$ & «o & $* *, 7097$ & Yr \\
\hline$* *, 799 \mathrm{~V}$ & 79 & $* * ., \neg \wedge \Gamma$ & $\sum 7$ & $* * \cdot, \wedge \wedge \cdot 1$ & rr \\
\hline
\end{tabular}


تابع جدول رقم (ץ): القيم التقديرية لمعاملات الصدق لبنود مقياس الضغوط النفسية المرتبطة بصعوبات التعلم بطريقة تحليل البنود

\begin{tabular}{|c|c|c|c|c|c|}
\hline ارتباط البند بالمقياس & رقبّ & ارتباط البند بالمقياس & رقبث & ارتباط البند بالمقياس & رقب \\
\hline$* *,, \wedge \wedge 9 \wedge$ & 117 & $* * \cdot, 971 r$ & 94 & $*, 0 \leqslant .0$ & $\checkmark \cdot$ \\
\hline$* *, \wedge \vee Y l$ & 118 & $* * \cdot, 9 \cdot \pi 0$ & $9 \varepsilon$ & $* \cdot, \cdot, Y \mu \Lambda$ & VI \\
\hline$* * \cdot, \wedge) 1$. & 111 & $* *, 9 r \leq 1$ & 90 & $* *, \wedge) \cdot 7$ & VY \\
\hline$* *, 0 \vee \leqslant 9$ & 119 & $* *, 7 \cdot r \mu$ & 97 & $* *, V Y \leq 1$ & vr \\
\hline$* *, \vee \vee Y q 1$ & ir. & $* *,, V \backslash \circ V$ & 9४ & $* *, \wedge \cdot \Sigma$. & $V \varepsilon$ \\
\hline$* *,, \wedge \wedge 0$. & $|Y|$ & $* * ., 9 \vee 99$ & $9 \wedge$ & $* *,, \wedge \wedge 01$ & vo \\
\hline$* *, T \vee \wedge r$ & ITr & $* \cdot, 09 \vee 0$ & 99 & $* *, 97 r$. & VT \\
\hline$* *, \wedge \circ r \mu$ & IrT & * •,77r & $1 \ldots$ & $* \cdot, 0, Y_{1}$ & $\checkmark V$ \\
\hline$* *,, 9 \leq 7 V$ & $1 Y \leq$ & $* *, 971 \%$ & $1 \cdot 1$ & $*$, Ar०q & $\vee \wedge$ \\
\hline 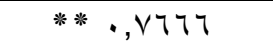 & lro & $* * \cdot, \wedge \neg 10$ & $1 \cdot r$ & $*, \vee \vee T r$. & $\vee q$ \\
\hline **, , 9r41 & 147 & $* * ., 9 \mu, 0$ & $1 \cdot r$ & $* *,, 9 \wedge \wedge 1$ & $\Lambda$. \\
\hline$* *, 9$, १ᄉ & ITV & $* \cdot, \wedge 99 \leq$ & $1 \cdot \varepsilon$ & $* *,, 9 \wedge \wedge 1$ & 人) \\
\hline$* *,, \vee 19$. & IrA & $* *,, T \cdot r$. & 1.0 & ***, •, & Ar \\
\hline$* *,, \wedge \wedge \uparrow$. & 149 & $* *, \wedge r V Y$ & 1.7 & *., OHMV & $\Lambda \mu$ \\
\hline$* *, 9711$ & $1 T$ & $* * \cdot, 9 \cdot r \wedge$ & $1 \cdot V$ & $* *,, 9 \leq \Lambda$. & $\Lambda \varepsilon$ \\
\hline$* *, 0119$ & IT & $* \cdot, V Y \cdot r$ & $1 \cdot 1$ & $*,, Y Y V \cdot$ & 10 \\
\hline$* *, \wedge \leq q \mu$ & אי & $* *, V 710$ & 1.9 & $* * \cdot, q \cdot r \varepsilon$ & 17 \\
\hline$* *, \wedge \wedge 01$ & Tr & $* ., 0.01$ & 11. & **, ,9777 & $\Lambda V$ \\
\hline$* * \quad,, \vee \vee \cdot 1$ & ITE & $* * \cdot, \wedge 97$. & 111 & $* *$, , Y r ^ & $\wedge \wedge$ \\
\hline & & $* *,, \vee \vee \neg \neg$ & $11 r$ & $* * \cdot, 719 r$ & 19 \\
\hline & & $* \cdot, 0 Y \leq \varepsilon$ & $11 \pi$ & $* * \cdot, \wedge \wedge \neg r$ & 9. \\
\hline & & $* *, \wedge r \leq \varepsilon$ & $11 \varepsilon$ & $* \cdot, 0119$ & 91 \\
\hline & & $* *, V, V \leq \varepsilon$ & 110 & $* *$, , VYOr & $q r$ \\
\hline
\end{tabular}

وبالنظر لقيم معامل الارتباط السابقة والكثف عن قيمتها الجدولية يتبين أنها تصل إلى مستوى عال من الدلالـة قيمته ( ا ., ·) وهذا يعني أن ثمـة تجانسا عاليا بين مكونـات هذه الاستبانة وهذا الأمر يحملنا على التتبؤ بصدقها. 
ثبات الاستبانة: نم حساب ثبات الاستبانة بأكثر من طريقة :

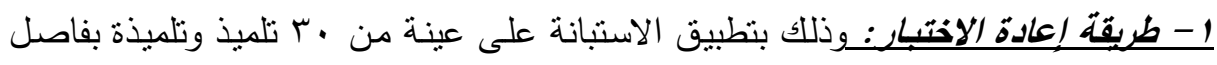

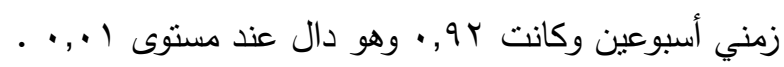

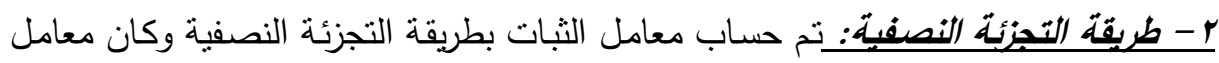

$$
\text { الارتباط ع^, • وهو دال على مستوى ل •,.•. }
$$

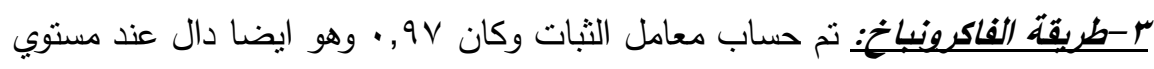

. ., 1

والجدول التالي يوضح حساب قيمة معامل الثبات

\begin{tabular}{|c|c|c|c|}
\hline إعادة الاختبار & ألفا كروتباخ & التجزئة النصفية & رقم البند \\
\hline., $971 \mathrm{~V}$ & $\cdot, \mathrm{V} \leq 0 \mathrm{r}$ & $\cdot, \vee \vee \neg \wedge 1$ & البناء المدرسي \\
\hline$\cdot, 91 \%$. & $\cdot, A K Y V$ & $\cdot, q \cdot \wedge v$ & المناهج الدراسية \\
\hline$\cdot, 9 \leq 7 r$ & $\cdot, \vee \backslash 19$. &., 9517 & الامتحانات \\
\hline., $9 \leq 0$. & .,人ץVq &., 0.9. & البيئة المدرسية \\
\hline$\cdot, \Lambda r \leqslant r$ &., 9100 & $\cdot, \wedge \wedge \wedge \uparrow$ & الخلافات الأسرية \\
\hline$\cdot, \wedge \leqslant Y q$ & $\cdot, 9 Y \vee V$ &., 910. & الرعاية الأسرية \\
\hline$\cdot, 910 \leqslant$ & $\cdot, \wedge \wedge \wedge \mathrm{V}$ &., $97 \leqslant$. & معاملة الوالدين للتلميذ \\
\hline., 9.09 &., 9717 &., $90 \ldots$ & البيئة الأسرية \\
\hline., $99 \wedge$. & $\cdot$, , Ат V &., $9|Y|$ & علاقة التلميذ بالمدرس \\
\hline., $9 \wedge 1 \pi$ & $\cdot, \wedge \uparrow q \leq$ & $\cdot, T \vee \wedge \wedge$ & علاقة التلمبذ بزملائه \\
\hline .,94וT &., 9.00 &., $91 \wedge$. & التفاعلات والعلاقات الاجتماعية \\
\hline$\cdot, 9 \leq 01$ & $\cdot, 0 \leqslant V \leqslant$ & $\cdot, r \leqslant Y q$ & عوامل صحية \\
\hline$\cdot, 99 \wedge 1$ &., $90 \cdot Y$ & $\cdot, 9109$ & عوامل نفسية \\
\hline., $99 Y \wedge$ &., $9 \leqslant 00$ & $\cdot, 9 \leqslant r V$ & العوامل الذاتية \\
\hline., 9191 &., $97 \vee \wedge$ & $\cdot, \wedge \Sigma \mid Y$ & المقياس الكلى \\
\hline
\end{tabular}

جدول (ه): القيم التقديرية لمعاملات ثبات مقياس الضغوط النفسية المرتبطة بصعوبات التعلم

يتضح من الجدول السابق أن الاستبانة ككل تتمتع بمعاملة ثابت عال مما يساعدنا على

التتبؤ بصدق هذه الاستبانة فضلا عن أن مكوناتها تتمتع بمعاملات ثبات مرتفعة. 


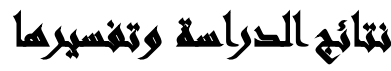

التساؤل الأول: هل توجد علاقة بين المساندة الإجتماعية وأساليب مواجهة ضغوط الحياة

لاى الأطفال الأين يعانون من صعويات التعلم؟

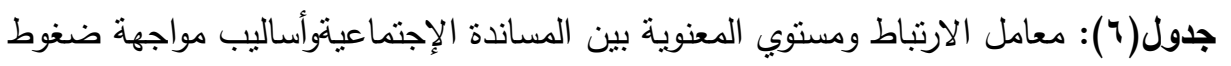

\begin{tabular}{|c|c|c|}
\hline ضغوط الحياة & \multicolumn{2}{|c|}{ عناصر المساندة الاجتماعية } \\
\hline 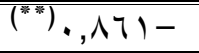 & معامل الارتباط & الأقران \\
\hline$(" *) \cdot, \wedge \leq Y-$ & معامل الارتباط & الأسرة \\
\hline$\left({ }^{* * *}\right) \cdot, \wedge \vee r-$ & معامل الارتباط & المعلم \\
\hline$\left({ }^{* *}\right) \cdot, 190-$ & معامل الارتباط & إجمالى المساندة \\
\hline
\end{tabular}

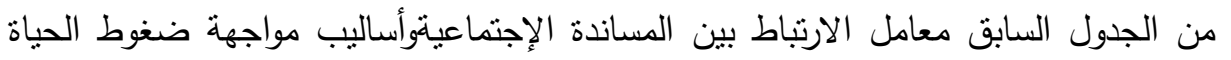

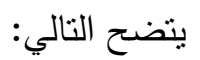

ه نوجد علاقة إرتباطية عكسية ذات دلالة إحصائية عند مستوى معنوية (0., •) بين

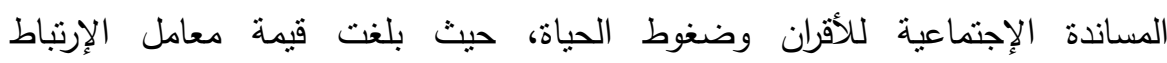

$$
\cdot(\cdot, \wedge T)-)
$$

ك نوجد علاقة إرتباطية عكسية ذات دلالة إحصائية عند مستوى معنوية (0., •) بين

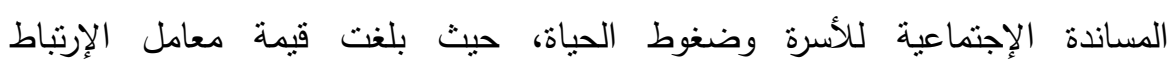

$$
\cdot(\cdot, V \leq r-)
$$

ه نوجد علاقة إرتباطية عكسية ذات دلالة إحصائية عند مسنوى معنوية (0., •) بين

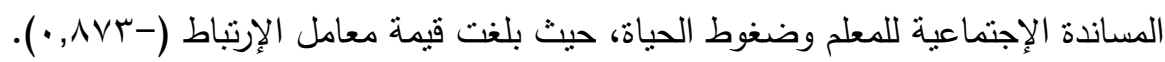
ك نوجد علاقة إرتباطية عكسية ذات دلالة إحصائية عند مستوى معنوية (0., •) بين المساندة الإجتماعية وأساليب مواجهة ضغوط الحياة، حيث بلغت قيمة معامل الإرنباط 
توجد علاقة ارتباطية عكسية بين المساندة الاجتماعية والضغوط النفسية لدى الأطفال

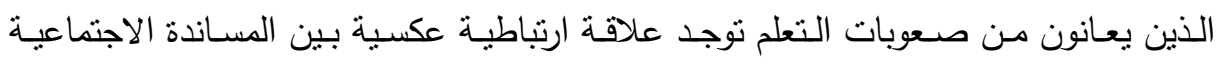

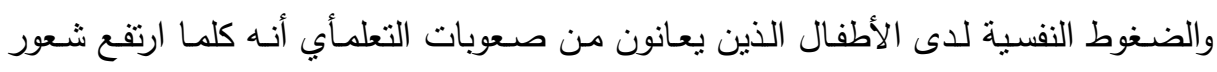

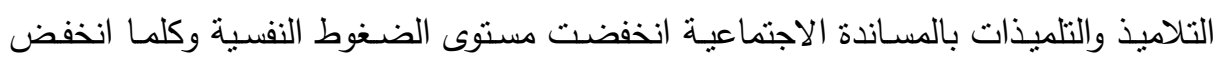

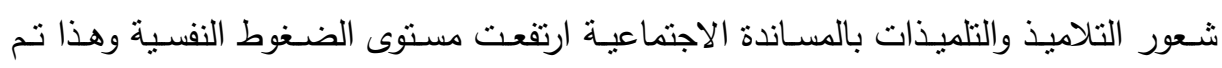
الإجابة على التساؤل الأول.

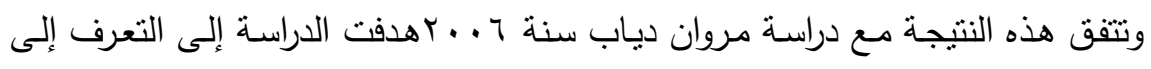

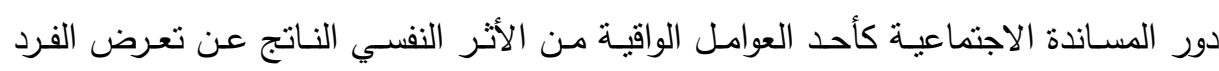

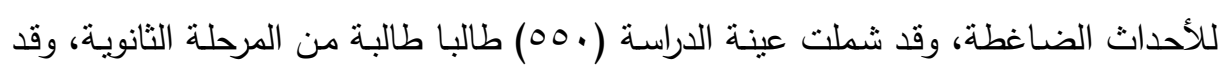

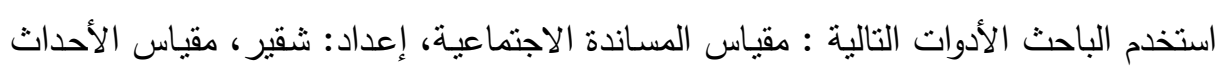

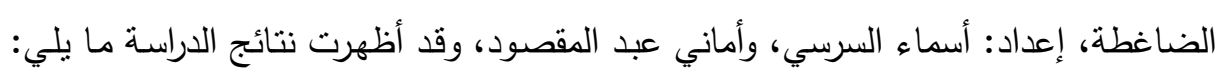

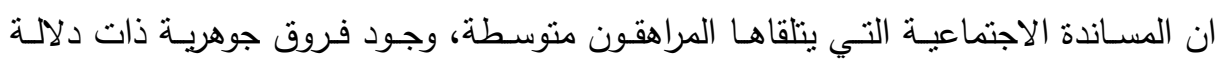

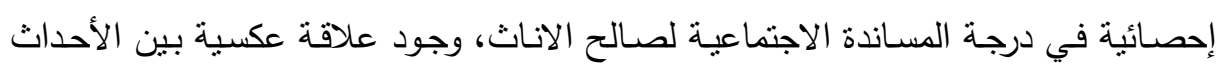

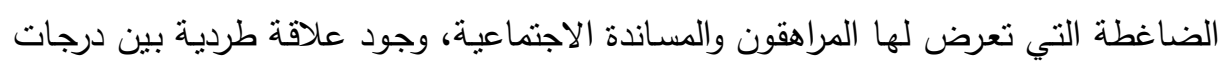
الصحة النفسية للمراقين، ودرجات المساندة الاجنماعية. وتتفق مع نظرية التعلق الوجداني التي تنص علي: هي نظرية بولبي تنص أن الأطفال

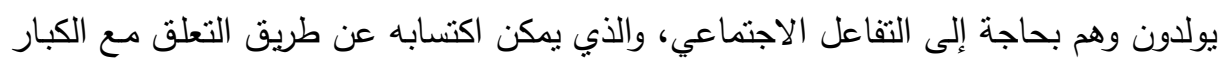

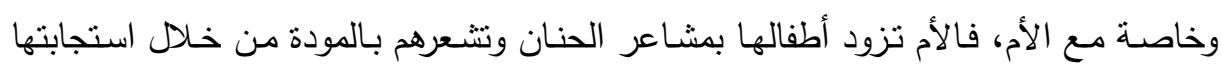

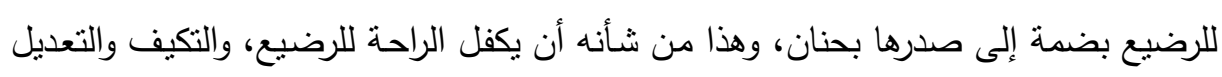

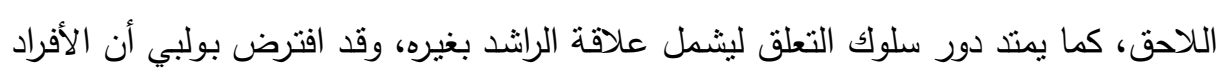

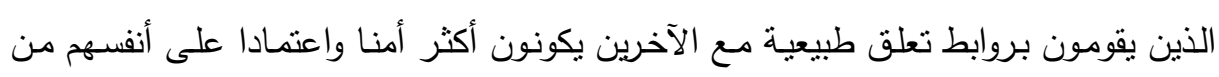
أولئك الذين يفتقدون هذه الروابط.

ويمكن مـن خـلال ذلك تفسير هذه النتيجـة فيمـا يخص مسـاندة الاجتماعيـة لأطفال

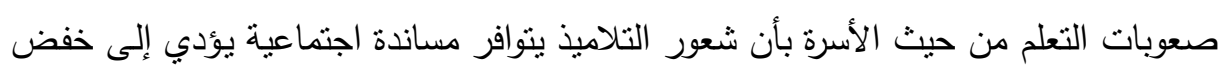
ضغوط النفسية لديه حيث أن الأسرة نساعده على تخطي المواد الدراسية الضعيفة وتوفر البيئة

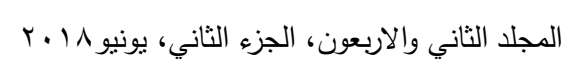




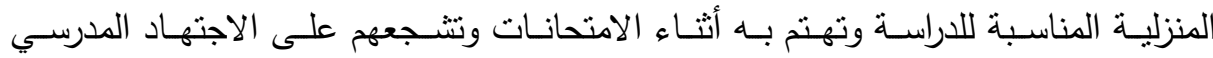
والاشتراك في الأنشطة المدرسية وأغلب الأسر منواصلة بشكل مستمر مع المدرسة وكل ذلك ونه

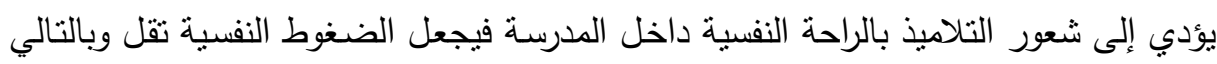
نسبة صعوبات التعلم عند الطفل تتخفض. ومن جانب أخر يمكن تفسير هذه النتيجة فيما يحض المعلم بأنه عندما يساند تلاميذه

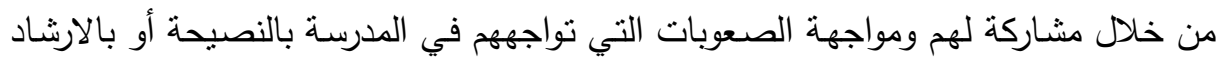

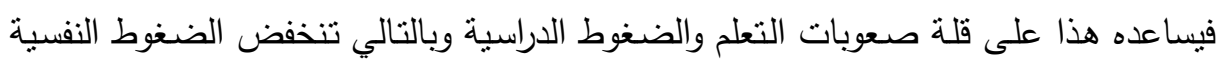
عند الطفل داخل المدرسة.

وكذللك تقسر الباحتون العلاقة ارتباطيه عكسية بين المساندة الاجتماعيـة والضغوط

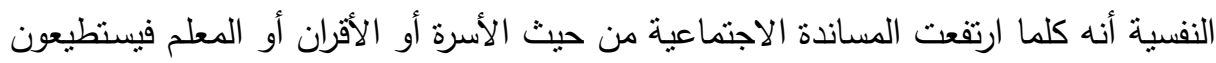

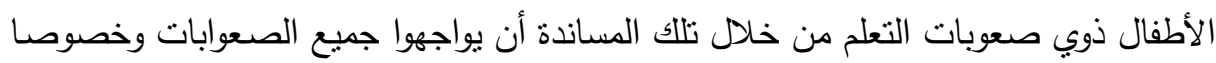
داخل المدرسة وبالتالي يسنطيعون التغلب على الضغوط النفئل التساؤل الثاني: هل توجد فروق بين الأطفال ذوي صعويات التعلم الذين يتلقون مساندة اجتماعية والذين لا يتلقون مساندة اجتماعية ويتعرضون لضغوط حياتية؟ جدول(V): معامل الارتباط بين المساندة الإجتماعية المنخفضة وأساليب مواجهة ضغوط

\begin{tabular}{|c|c|c|}
\hline ضفوط الحياة & لاجتماعية & عناصر ال ع \\
\hline$\cdot, \cdot 1 \Gamma$ & معامل الارتباط & الآقران \\
\hline$\cdot, \varepsilon \vee-$ & معامل الارتباط & الأسرة \\
\hline$\cdot, \cdot \wedge \vee-$ & معامل الارتباط & 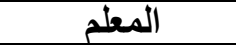 \\
\hline$\cdot$, Y VOO- & معامل الارتباط & إجمالى المساندة \\
\hline
\end{tabular}

من الجدول السابق يتضح عدم وجود معامل الارتباط ذات دلالة إحصائية عند مستوى معنوية (0., •) بين المساندة الإجتماعية المنخفضة وأساليب مواجهة ضغوط الحئة الحياة، حيث

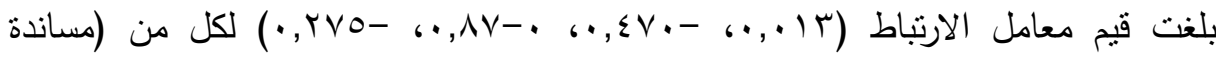
الأقران - مساندة الأسرة - مساندة المعلم - إجمالي المساندة) وهي قيم غير دالة إحصائياً

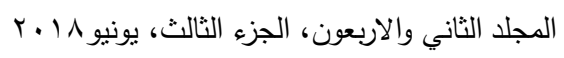


جدول(^): معامل الارتباط ومسنوي المعنوية بين المساندة الإجتماعية المرتفعة وأساليب مواجهة ضغوط الحياة

\begin{tabular}{|c|c|c|}
\hline ضغوط الحياة & \multicolumn{2}{|c|}{ عناصر المساندة الاجتماعغية } \\
\hline$\cdot, \Gamma \wedge \varepsilon-$ & معامل الارتباط & الأقران \\
\hline$\cdot, 719-$ & معامل الارتباط & الأسرة \\
\hline$\cdot, \varepsilon, 0-$ & معامل الارتباط & المعلم \\
\hline$\cdot, 0 \leqslant V-$ & معامل الارتباط & إجمالي المساندة \\
\hline
\end{tabular}

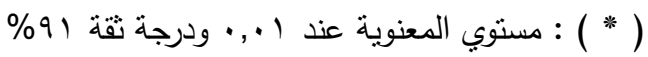

من الجدول السابق معامل الارتباط بين المساندة الإجنماعية|لمرتفعة وأساليب مواجهة ضغوط الحياة ينضح التالي:

ه ل انوجد علاقة إرتباطية ذات دلالة إحصائية عند مستوى معنوية (0., •) بين المساندة الإجتماعية المرتفعة للأقران وضغوط الحياة، حيث بلغت قيمة معامل الإرتباط

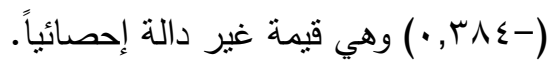
توجد علاقة إرتباطية عكسية ذات دلالة إحصائية عند مستوى معنوية (0., •) بين إناتيا.

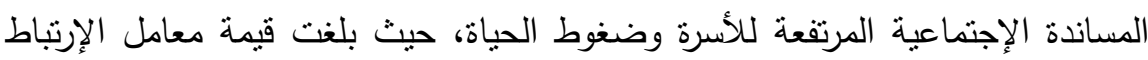

ه لا توجد علاقة إرتباطية عكسية ذات دلالة إحصائية عند مستوى معنوية (0., •) بين المساندة الإجتماعية المرتفعة للمعلم وضغوط الحباة، حيث بلغت قيمة معامل الإرتباط

$$
\text { (-0 • ع , • ) وهي قيمة غير دالة إحصائياً. }
$$

ه توجد علاقة إرتباطية عكسية ذات دلالة إحصائية عند مستوى معنوية (ه.,.•) بين المساندة الإجنماعية المرتفعة وأساليب مواجهة ضغوط الحياة، حيث بلغت داطت قيمة معامل

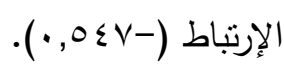

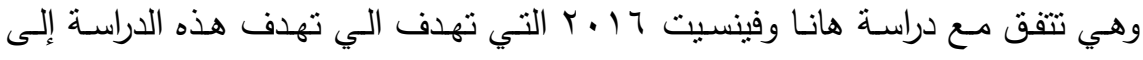
البحث في علاقة بين المساندة الاجتماعية والضغوط لدى طلاب الجامعة في مرحلة البكالوريا والمقارنة بين المساندة الاجتماعية والضغوط بين مستويات التعليم المختلفة على عينة قوامها

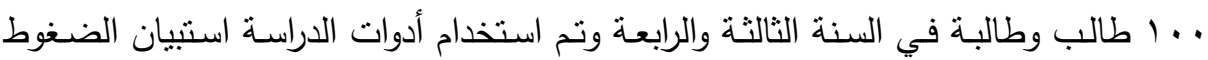

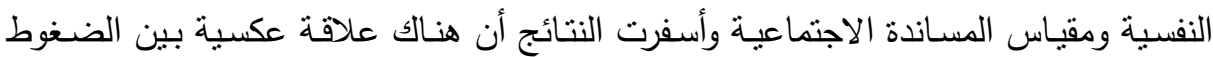

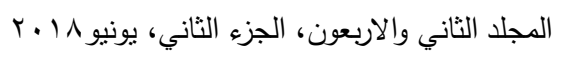


والمسـاندة الاجتماعية حيث أن الطلاب الذين يحصلون على مساندة اجتماعيـة يعانون من ضغوط نفسية قليلة .

وتتفق مع نموذج الواقي المخفف الذي يعتبر المساندة الاجتماعية أحد التغيرات النفسية

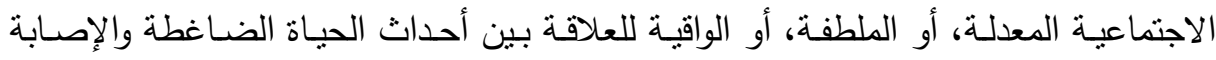

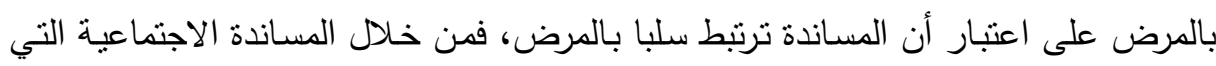

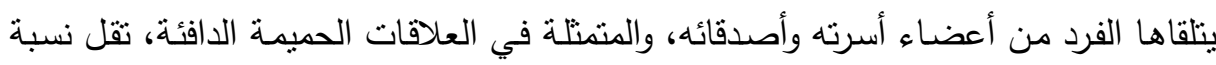

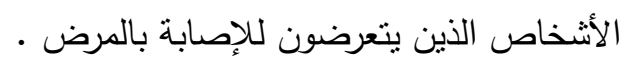

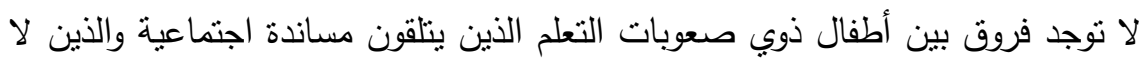

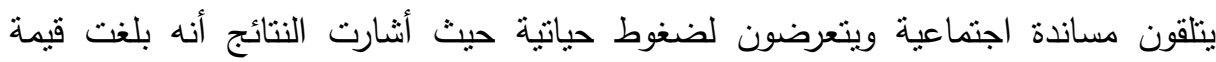

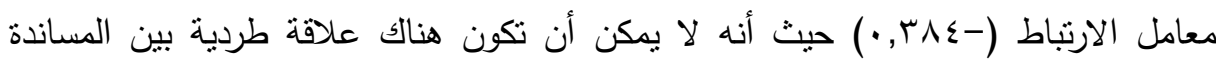
الاجتماعية والضغوط النفسية وبالتالي فإن لا توجد فروق بين أطفال صعوبات التعلم ولكن

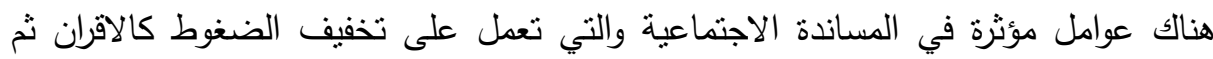
الأسرة ثم المعلم

التساؤل الثالث: هل يؤثر نوع الطقل من ذوي صعويات التعلم على مستوى مساندة

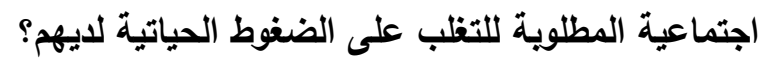
جدول(9): معامل الارتباط ومستوي المعنوية بين المساندة الإجتماعية وأساليب مواجهة ضغوط الحياة لعينة الذكور

\begin{tabular}{|c|c|c|}
\hline ضغوط الحياة & \multicolumn{2}{|c|}{ عناصر المساندة الاجتماعية } \\
\hline$", \wedge \vee \Gamma-$ & معامل الارتباط & الأققران \\
\hline$*, \wedge \leq \varepsilon-$ & معامل الارتباط & الأسرة \\
\hline$\because, \Lambda \vee \mu-$ & معامل الارتباط & المعلم \\
\hline$\cdot, 9 \cdot \varepsilon-$ & معامل الارتباط & إجمالي المساندة \\
\hline
\end{tabular}


من الجدول السابق معامل الارتباط بين المساندة الإجتماعيةلعينة الذكور وأساليب مواجهة ضغوط الحياة بتضح التالي: ه نوجد علاقة إرتباطية عكسية ذات دلالة إحصائية عند مستوى معنوية (0., •) بين

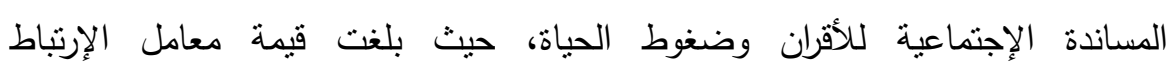
$\cdot(\cdot$, , NVT-)

ه نوجد علاقة إرتباطية عكسية ذات دلالة إحصائية عند مستوى معنوية (0.,.) بين

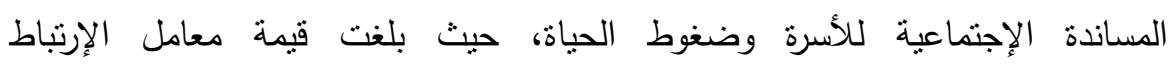
$\cdot(\cdot, \wedge \leq \varepsilon-)$

ه توجد علاقة إرتباطية عكسية ذات دلالة إحصائية عند مستوى معنوية (0., •) بين

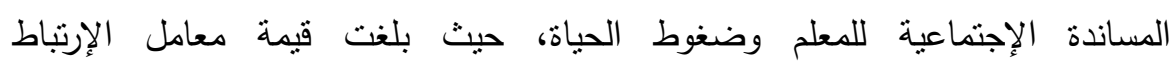
$\cdot\left(\cdot, \wedge \vee Y^{-}\right)$ ه توجد علاقة إرتباطية عكسية ذات دلالة إحصائية عند مستوى معنوية (0., ) ) بين المساندة الإجتماعية وأساليب مواجهة ضغوط الحياة، حيث بلغت قيمة معامل الإرتباط $\cdot(\cdot, 9 \cdot \varepsilon-)$ ه يتبين من جدول رقم (ع) وجود علاقة ارتباطية عكسية بين المساندة الاجتماعية والضغوط

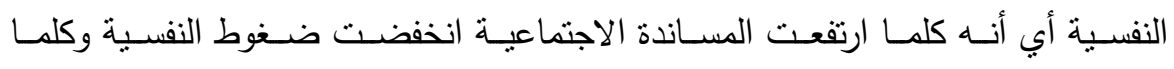
انخفضت مساندة الاجتماعية ارتفعت ضغوط النفسية حيث أنه اتفقت بعض الدراسات مع التع هذه النتيجة التي أوضحت نتائجها أن الضغوط النفسية مرتبطة بالمساندة اجتماعية ارتباط

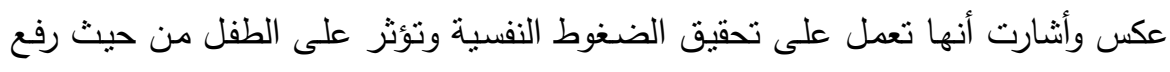
النقة في النفس عندما ينلقى المساندة الاجتماعية في الأسرة أو الأقران أو المعلم.

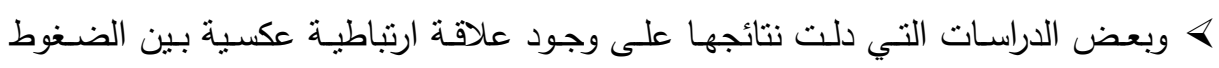
النفسية والمساندة الاجتماعية لدى طالبات جامعة. 
جدول (• (1): اختبار ت T-Test لتوضيح الفروق بين عينة الدراسة تبعاُ لمتغير النوع لمتغيرات الاستبيان

\begin{tabular}{|c|c|c|c|c|c|c|}
\hline المعنوية & قيمة ت & الإنحرف المعياري & المتوسط & العدد & |النوع | & المتغيرات \\
\hline \multirow{2}{*}{$\cdot, \wedge$} & \multirow{2}{*}{$\cdot, r) \leqslant$} & $7 Y, 11$ & $107, \ldots$ & $T V$ & | ذكر & \multirow{2}{*}{ ضغوط نفسية } \\
\hline & & Or,^q & $1 \leqslant \wedge, \cdots$ & $r$ & أنثى & \\
\hline \multirow{2}{*}{$\cdot, r$} & \multirow{2}{*}{$1, r \cdot 1$} & $7, \Gamma \varepsilon$ & 17,10 & TV & ذكر & \multirow{2}{*}{ الأقران } \\
\hline & & $V, 9 \varepsilon$ & $r Y, \cdots$ & $r$ & أنثى & \\
\hline \multirow{2}{*}{$\cdot, 0$} & \multirow{2}{*}{ - , VOr } & $0, \wedge 1$ & $19, Y Y$ & TV & ذكر & \multirow{2}{*}{ الأسرة } \\
\hline & & $\Lambda, V Y$ & $r, \ldots$ & $\mu$ & أنثى & \\
\hline \multirow{2}{*}{$\cdot, \varepsilon$} & \multirow{2}{*}{$\cdot, \vee \vee \vee \neg$} & $0,9$. & 10,11 & TV & ذكر & \multirow{2}{*}{ المعلم } \\
\hline & & $V, O V$ & $1 \wedge, 7 V$ & $r$ & أنثى & \\
\hline \multirow{2}{*}{ • } & \multirow{2}{*}{$\cdot, 99 \leqslant$} & $I V, Y \leq$ & 01,19 & TV & ذكر & \multirow{2}{*}{ مساندة|جتماعية } \\
\hline & & $r \varepsilon, \cdot 1$ & $T Y, T V$ & $r$ & أنثى & \\
\hline
\end{tabular}

الجدول السابق يوضـح الفروق بين عينة الدراسـة تبعاُ لمتغير النوع لمتغيرات الاستنيان

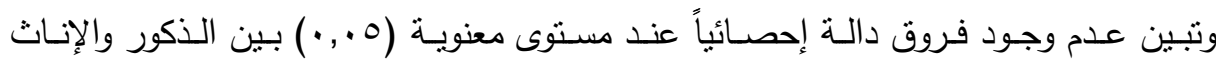
للضـغوط النفسية والمسـاندة الاجتماعيـة ويتضـح من جدول (0) عدم وجود علاقة ارتباطيـة

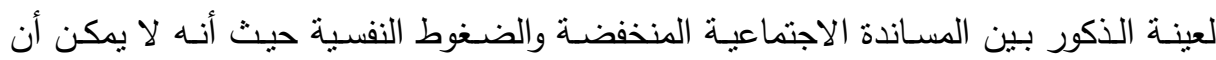
تكون الضغوط النفسية قليلة وأيضا المساندة الاجتماعية منخفضة.

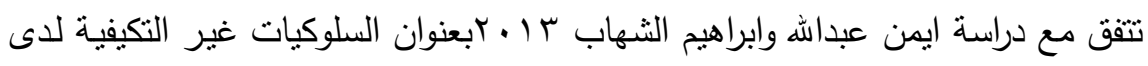
طلبة صعوبات التعلم في المرحلة الأساسية الدنيا، هدفت الدراسة إلى التعرف على التى السلوكيات

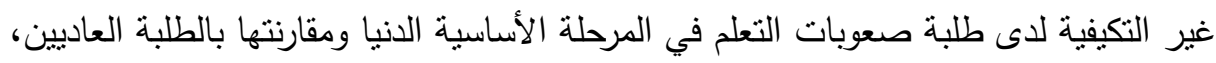

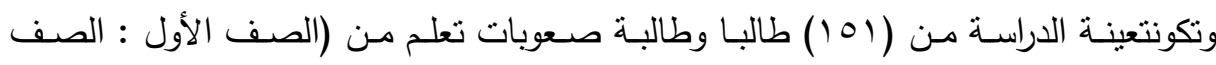

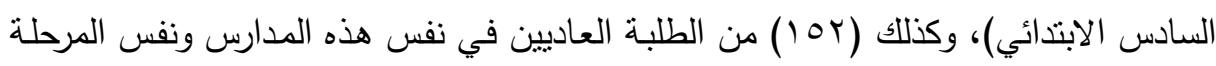
العمرية، ولقد استخدم الباحثان مقياس (وولكر) للسلوكيات غير التكيفية، وأثنارت نتائج الدراسة الأنة إلى أن السلوكيات غير التكيفية لاى طلبة صعوبات التعلم هي: السلوك الموجه نحو الخارج،

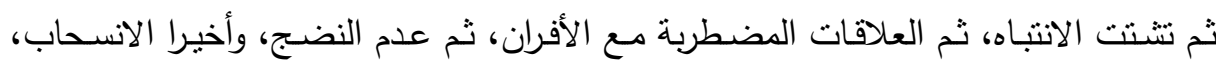


ووجود فروق لصالح الذكور على مستوى تشتت الانتباه، ولصالح الإناث على مستوى عدم النضج.

وتتفق مـع الاطـار السلوكي حيث يرى أصحاب هذا الإطـار أنـهـ من الضروري دراسـة

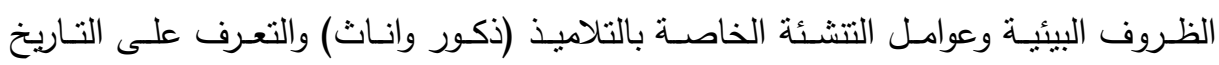

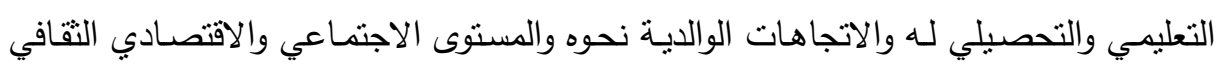
لأسرته فقد لا تتاح له في كنفها الخبرات والمثيرات التربوية التي تقدح زناد قدراته العقلية وهو التهو

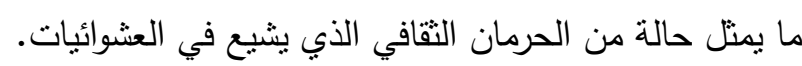

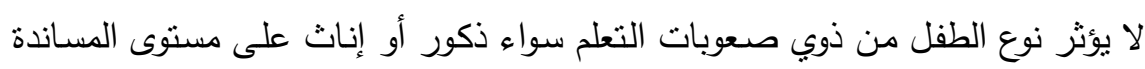

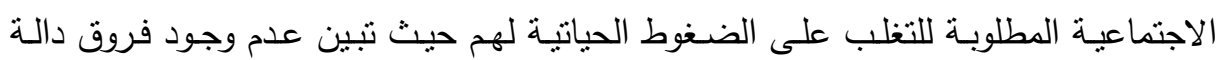
احصـائيا عند مسنوى المعنويـة (0. . •) بين الذكور والإنـاث فطفل صسعوبات التعلم يحتاج للمساندة الاجتماعية في الأسرة والمعلم والاقران.

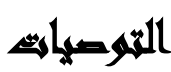

توصيات خاصة بالأسرة: ضرورة توفير الأسرة لأبنائها مساندة اجتماعية قوية لأن الأبناء الذين يفتقدون مساندة الأسرة يفشلون ولا يستطيعون أن يتكيفوا مع المواقف المدرسية.

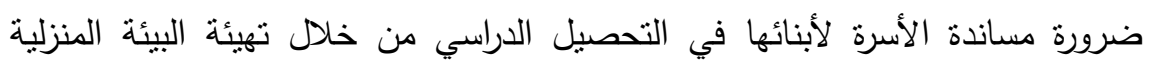
المناسبة التي نساعد على حسن سير العملية التعليمية.

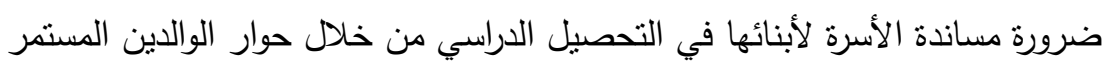

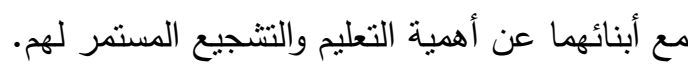

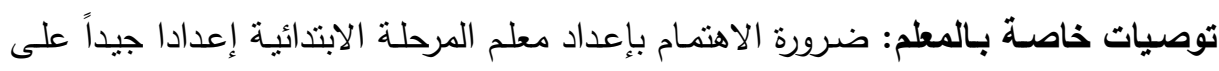
أسس علمية وتربوية صحيحة حتى يسنطيع أن يقدم المساندة الاجتماعية القوية للتلاميذ.

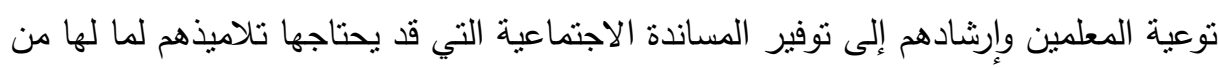
تأثثر قوي ومباشر على تخفيف الضغوط النفسية للتلاميذ. لابد من توعية المعلم على مشاركة تلاميذه وتتجيعهم وتقديم المعلومات التي يحتاجون إلبيها لتحسين سلوكهر من لوعه 
توصيات خاصة بالأقران:

• تشجيع التلاميذ على التعاون مع أقرانهم ومشاركتهم ألعابهم ونشاطاتهم بواسطة الاخصائي النفسي. • معالجة المشكلات البسيطة التي يواجهها التلاميذ مع زملائهم أو أصدقائهم مما يساعدهم على التكيف السوي بواسطة الاخصائي النفسي.

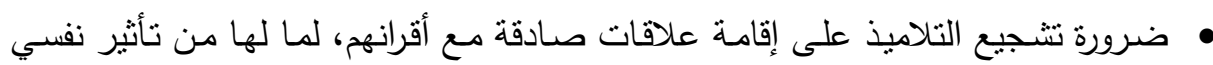
إيجابي عليهم، حيث إن التلميذ في هذه المرحلة قد يستخدم صديقه في الفصل كمصدر للمساندة يساعده على تخفيف الضغوط النفسية لديه بواسطة الاخصائي النفسي.

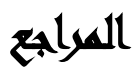

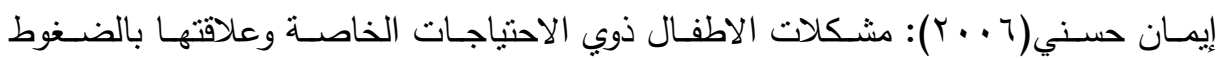
النفسية للآباء (دراسة مقارنة)، رسالة دكتوراه غير منشورة، معهد دراسات العليا للطفولة، جامعة عين شمس

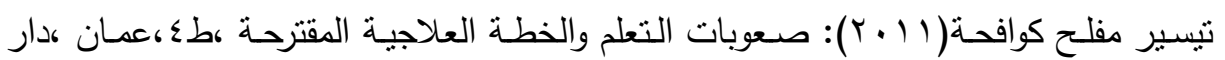
المسيرة للنشر والتوزيع والطباعة حنان ثابت مدبولي( ( . ب): الضغوط الاجتماعية المدرسية وعلاقتها بوجهة الضبط ودافعية الانجاز لدي الاطفال، رسالة ماجستير منشورة ،معهد الدراسات العليا للطفولة،

$$
\text { جامعة عين شمس. }
$$

سليمان عبد الواحد( • ( ؟ ): المرجع في صعوبات التعلم النمائية والاكاديمية،القاهرة ،مكتبة

$$
\text { الانجلو المصرية }
$$

علي عبد السلام(0 . ㄷ): المساندة الاجتماعية وتطبيقاتها العملية ،ط (القاهرة ،مكتبة النهضة

$$
\text { المصرية }
$$

علي منصور ابو طال(1) (1)): المساندة الاجتماعية وعلاقتها بالأمن النفسي لدي عينة من

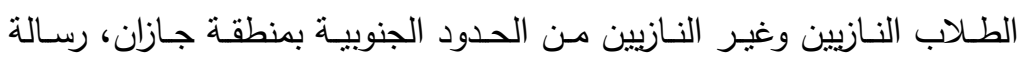

$$
\text { ماجستير غير منشورة،جامعة أم القري،مكة المكرمة }
$$

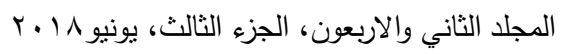




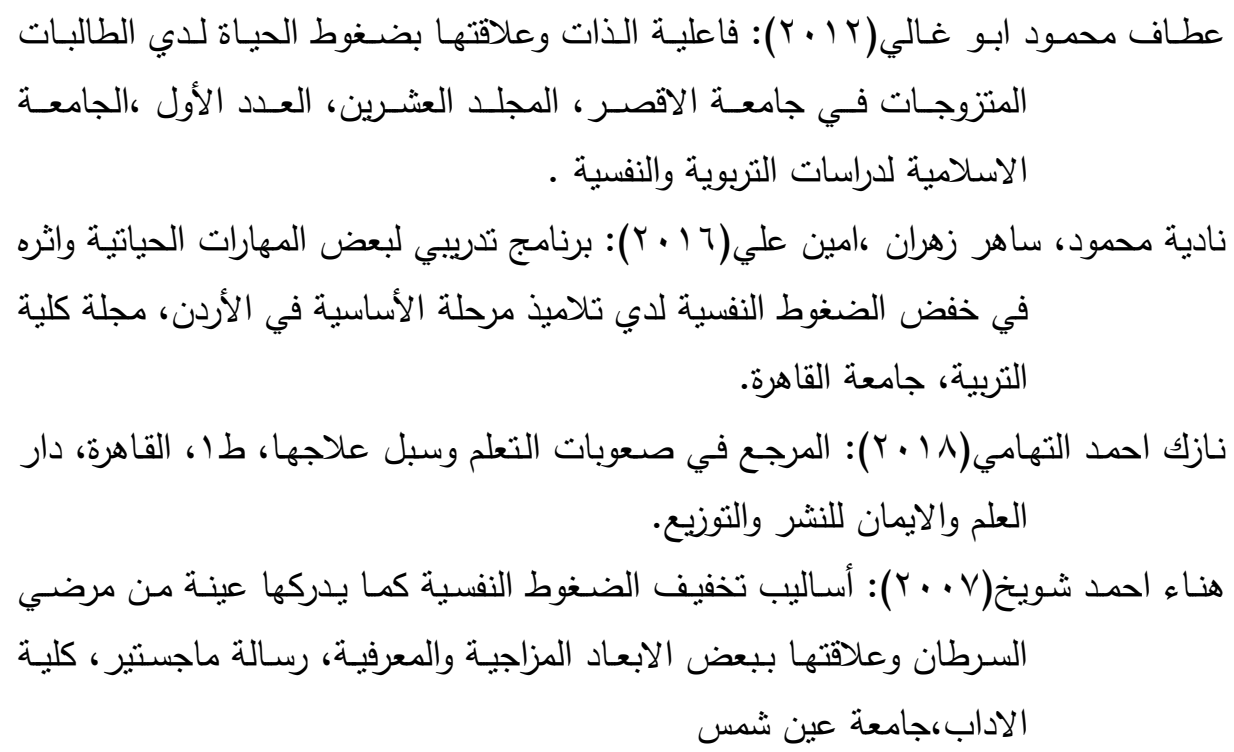

Bauman, Emily mara (2009) : social support and loss of resources as predictors of mental health and quality of life in battered women over time dissertation abstracts international, B vol., 69 (7-B), pp.4409.

Charyton, christine, Eliott, john, Lue, JLayne (2009) : the impact of social support on health related quality of life in persons with epilepsy. Epilepsy and Behavior, vol 16 (4), pp645.

Dyson, R ,enk (2006) : Freshmen adaptation to university life. Depressive symptoms stress and coping Journal of clinical psychology.62 (10),208-220.

Maggie mamen (2007): under standing nonverbal learning disabilities ca common sense guide for parents and professional jessicakingsley publishers, London and Philadelphia. 


\title{
THE ROLE SOCIAL SUPPORT RELIEVING THE PRESSURES OF LIFE IN CHILDREN WITH LEARNING DIFFICULTIES
}

\author{
karam Eldin, Laila ${ }^{(1)}$; Abd Almanem, A. ${ }^{(2)}$ \\ and Madni, Samia, M.
}

1) Institute of postgraduate childhood Studies, Ain Shams University

2) Institute of Institute of environmental Studies of Research, Ain Shams University

\begin{abstract}
The study aimed at revealing the role of social support in alleviating the stress of life in children with learning difficulties and the sample was selected from 30 students which are 27 males and 3 females. The students were classified as children with learning difficulties from the basic education school in Cairo governments( the Manra of El-Emanprivate) school for languages in Educational Administration, East Nasr City the $10^{\text {th }}$ district in the academic year (2017 - 2018). They are between 9-11 years old. The study used descriptive method and adopted the study scale prepared by the researcher Maha Jar Allah Hassan 2004 and the psychological stress assessment prepared by the researcher Madiha Abdel Aziz Mohamed El Gamal 2004. The results of this study were as follows: - There is an inverse correlation between statistical support and social support and methods of coping with life pressures. The results should guide the following recommendations: the family should be made aware of not having their problems as failure to support children at this stage. Educating teachers must provide the necessary support that students may need to reduce psychological stress. Encourage students to be collaborated with their friends and share their games.
\end{abstract}

Key words: socialsupport - pressuresoflife - learningdifficulties.

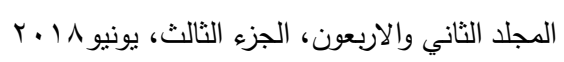

